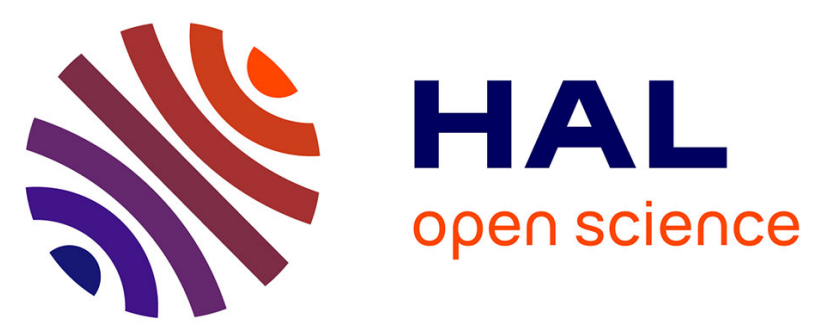

\title{
A new pyrimidinium tetrachloroferrate(III) salt with a low band gap: Hirshfeld surface analysis, crystal structure and physicochemical studies
}

Kamel Kaabi, Frédéric Lefebvre, V. Ferretti, Christian Jelsch, Cherif Ben Nasr

\section{- To cite this version:}

Kamel Kaabi, Frédéric Lefebvre, V. Ferretti, Christian Jelsch, Cherif Ben Nasr. A new pyrimidinium tetrachloroferrate(III) salt with a low band gap: Hirshfeld surface analysis, crystal structure and physicochemical studies. Journal of the Iranian Chemical Society, 2020, 17 (9), pp.2317-2326. 10.1007/s13738-020-01928-9 . hal-03003509

\section{HAL Id: hal-03003509 \\ https://hal.science/hal-03003509}

Submitted on 13 Nov 2020

HAL is a multi-disciplinary open access archive for the deposit and dissemination of scientific research documents, whether they are published or not. The documents may come from teaching and research institutions in France or abroad, or from public or private research centers.
L'archive ouverte pluridisciplinaire HAL, est destinée au dépôt et à la diffusion de documents scientifiques de niveau recherche, publiés ou non, émanant des établissements d'enseignement et de recherche français ou étrangers, des laboratoires publics ou privés. 


\title{
A new pyrimidinium tetrachloroferrate(III) salt with a low band gap:
}

\section{Hirshfeld surface analysis, crystal structure and physicochemical studies}

Kamel Kaabi ${ }^{1 *}$, Frédéric Lefebvre ${ }^{2}$, V. Ferretti ${ }^{3}$, Christian Jelsch $^{4}$, Cherif Ben Nasr ${ }^{1}$

1 Laboratoire de Chimie des Matériaux, Université de Carthage, Faculté des Sciences de Bizerte, 7021 Zarzouna, Tunisie.

2 Laboratoire de Chimie Organométallique de Surface (LCOMS), Ecole Supérieure de Chimie Physique Electronique, 69626 Villeurbanne Cedex, France.

3 Department of Chemical and Pharmaceutical Sciences and Center for Structural Diffractometry, Via Fossato di Mortara 17, I-44121 Ferrara, Italy

4 CRM2, CNRS, Institut Jean Barriol, Université de Lorraine, Vandœuvre les Nancy Cedex, France.

*Corresponding author: Kamel Kaabi, Email address: kamel_kaabi@yahoo.fr

\begin{abstract}
The chemical preparation, characterization by single crystal X-ray diffraction, elemental analysis and IR spectroscopy of the new Fe(III) complex $\left(\mathrm{C}_{5} \mathrm{H}_{7.50} \mathrm{~N}_{3} \mathrm{O}\right)_{2}\left[\mathrm{FeCl}_{4}\right]$ are reported. The Fe(III) cation is four-coordinated, in tetrahedral fashion, by four chlorine atoms. The $\left[\mathrm{FeCl}_{4}\right]^{-}$tetrahedra are located parallel to the $(\mathbf{a}, \mathbf{b})$ plane at $z=1 / 4(2 n+1)$ between layers of organic cations $\left(\mathrm{C}_{5} \mathrm{H}_{7.50} \mathrm{~N}_{3} \mathrm{O}\right)_{2}{ }_{2}^{+}$. The $\mathrm{FeCl}_{4}$ moieties are inserted between these planes by establishing $\mathrm{N}-\mathrm{H} . . . \mathrm{Cl}$ and $\mathrm{C}-\mathrm{H} . . . \mathrm{Cl}$ hydrogen bonds generated by amino and methyl groups as donors and $\mathrm{Cl}^{-}$anions as acceptors to form a three-dimensional network. The organic groups are linked together by $\mathrm{N}-\mathrm{H}$...N hydrogen bonds to form chains extending along the [110] direction. These chains are arranged in planes parallel to $(\mathbf{a}, \mathbf{b})$ at $z=1 / 2 n$. Intermolecular contacts on the Hirshfeld surface were investigated statistically. The most favored and stabilizing contacts are the strong $\left(\mathrm{N}-\mathrm{H} \ldots \mathrm{Cl}^{-}, \mathrm{N}-\mathrm{H} \ldots \mathrm{N}\right)$ hydrogen bonds as well as the weaker ones $\mathrm{C}-\mathrm{H} . . . \mathrm{Cl}^{-}$. The vibrational absorption bands were identified by infrared spectroscopy. Electronic properties such as HOMO and LUMO energies were also derived.
\end{abstract}

Keywords: Hirshfeld surface $\bullet$ Contacts enrichment $\bullet$ Quantum mechanics $\bullet$ X-ray diffraction - Coordination compound 


\section{Introduction}

The design and synthesis of hybrid compounds have been of interest in recent years because of their potential applications in the fields of magnetism, photoluminescence, optoelectronics, catalysis and medicals or pharmaceuticals [1-4]. Among these compounds, iron complexes attract considerable attention. Iron is the most abundant element in the environment and plays a crucial role in the survival of terrestrial organisms. Several iron (III) complexes are known as contrast agents for magnetic resonance imaging (MRI) [5]. They are also known in catalytic, antitumor and antimicrobial domains [6-10]. As a contribution to the study of these materials, we undertook the synthesis of a Fe(III) complex containing a 4-amino-6methoxypyrimidinium organic cation which was chosen for its practical importance. Indeed, pyrimidines and their derivatives are simple aromatic compounds consisting of two nitrogen atoms and four carbon atoms. The carbon and nitrogen atoms are connected by alternating double and single bonds. This bonding structure allows for resonance, or aromaticity, causing the ring to be very stable. They are of extreme importance since three of the four nucleic bases of DNA, namely cytosine, thymine and uracil are pyrimidine derivatives. We report in this article the Hirshfeld surface analysis of this compound. This analysis was performed to characterize the intermolecular interactions and explain the crystal architecture. In addition, the complex was studied by spectroscopy and DFT calculations were used for the interpretation of the vibration results. 


\section{Experimental}

\section{Chemical preparation}

Hydrochloric acid $\mathrm{HCl}$ 37\% (0.4 mmol, Sigma-Aldrich) dissolved in $10 \mathrm{~mL}$ of ethanol was added dropwise to a mixture of iron(III) chloride $\mathrm{FeCl}_{3} 97 \%$ (0.4 mmol, Sigma-Aldrich) and 4-amino-6-metoxypyrimidine (0.4 mmol, Sigma-Aldrich) dissolved in $20 \mathrm{ml}$ of ethanol. The whole was stirred at room temperature for 40 minutes until disappearance of precipitate and then the solution was covered with a cellophane paper. The resulting solution was kept at ambient temperature until formation of single crystals of sufficient size for the structural study. These crystals remained stable under normal conditions of temperature and humidity (yield 72\%). Anal. Calc.: C, 26.73; H, $3.34 \%$; , $18.17 \%$. Found: C, 26.40; H, 3.63; N, $18.78 \%$.

\section{X-ray single crystal structural analysis}

A single crystal suitable to X-ray diffraction analysis was carefully selected under polarizing microscope. Diffraction data were collected on a Nonius Kappa diffractometer equipped with a CCD detector with graphite-monochromatized $\mathrm{MoK} \alpha$ radiation $(\lambda=0.71069$ $\AA$ ). Intensities were corrected for Lorentz, polarization and absorption effects [11]. The structure was solved by direct methods with the SIR97 suite of programs [12] and refinements were performed on $F^{2}$ by full-matrix least-squares methods with all non-hydrogen atoms anisotropic. C-H hydrogens were included on calculated positions, riding on their carrier atoms; all other hydrogen atoms were located in the Difference Fourier map and refined isotropically. All calculations were performed using SHELXL-97 [13] implemented in the WINGX system of programs [14]. The crystal data are reported in Table 1. The drawings were made with Diamond [15] and Mercury [16].

\section{Infrared spectroscopy}


The IR spectra were recorded in the range $4000-400 \mathrm{~cm}^{-1}$ with a "Perkin-Elmer FTIR" spectrophotometer1000 using samples dispersed in spectroscopically pure $\mathrm{KBr}$ pressed into a pellet.

Table 1 Experimental details of $\left(\mathrm{C}_{5} \mathrm{H}_{7.50} \mathrm{~N}_{3} \mathrm{O}\right)_{2}\left[\mathrm{FeCl}_{4}\right]$

\begin{tabular}{ll}
\hline Crystal data & \\
Chemical formula & $2\left(\mathrm{C}_{5} \mathrm{H}_{7.50} \mathrm{~N}_{3} \mathrm{O}\right) \cdot \mathrm{Cl}_{4} \mathrm{Fe}$ \\
$M_{\mathrm{r}}$ & 448.93 \\
Crystal system, space group & Triclinic, $P 1$ \\
Temperature $(\mathrm{K})$ & 295 \\
$a, b, c(\AA)$ & $6.6406(2), 7.4042(3), 19.6212(7)$ \\
$\alpha, \beta, \gamma\left({ }^{\circ}\right)$ & $88.350(3), 87.005(3), 77.210(2)$ \\
$V\left(\AA^{3}\right)$ & $939.37(6)$ \\
$Z$ & 2 \\
Radiation type & Mo Ka \\
$\mu\left(\mathrm{mm}^{-1}\right)$ & 1.39 \\
Crystal size $(\mathrm{mm})$ & $0.29 \times 0.12 \times 0.12$ \\
Data collection & \\
Diffractometer & Nonius Kappa CCD \\
Absorption correction & Multi-scan \\
$T_{\min }, T_{\max }$ & $0.805,0.864$ \\
No. of measured, independent and & $12546,4036,2999$ \\
$R_{\text {int }}$ & 0.041 \\
$(\text { sin } \theta / \lambda)_{\max }\left(\AA^{-1}\right)$ & 0.639 \\
Refinement & \\
$R\left[F^{2}>2 \sigma\left(F^{2}\right)\right], w R\left(F^{2}\right), S$ & $0.039,0.106,1.04$ \\
No. of reflections & 4036 \\
No. of parameters & 232 \\
$\Delta \rho_{\max }, \Delta \rho_{\min }\left(\mathrm{e} \AA^{-3}\right)$ & $0.63,-0.47$ \\
\hline
\end{tabular}

\section{DFT calculations}

The calculations were made with the Gaussian 09 revision A-02 software [17]. The starting geometry was that obtained from the X-ray structure. The positions of the protons were optimized, all other atoms being in the positions given by the X-ray diffraction study. The result of this optimization is an elongation of the $\mathrm{CH}$ and $\mathrm{NH}$ bonds and a displacement of the hydrogens of the $\mathrm{NH}_{2}$ groups out of the plan of the aromatic cycle. These calculations were 
made with the pseudo-potential LanL2DZ for iron and the base $6-31+\mathrm{G}^{*}$ for all other atoms $(\mathrm{C}$, $\mathrm{H}, \mathrm{N}, \mathrm{O}$ and $\mathrm{Cl})$.

\section{Results and discussion}

\section{X-ray diffraction study}

$\mathrm{X}$-ray diffraction analysis of the complex $\left(\mathrm{C}_{5} \mathrm{H}_{7.50} \mathrm{~N}_{3} \mathrm{O}\right)_{2}\left[\mathrm{FeCl}_{4}\right]$ reveals that this compound crystallizes in the triclinic space group P $\overline{1}$ Its asymmetric unit, shown in Fig. 1, contains a tetrachloroferrate (III) $\left[\mathrm{FeCl}_{4}\right]^{-}$anion and two organic molecules of 4-amino-6methoxypyrimidine. Each molecule is forming a homodimer via an inversion center. From electroneutrality appears that one of the ligands is in cationic form (pyrimidinium), while another is in neutral form. Here the crystal symmetry does not permit distinguishing between protonated and neutral forms of pyrimidine ligands. In fact, it is disorder originating from the close position of hydrogen atoms $\mathrm{H} 6 \mathrm{~N}$ and $\mathrm{H} 5 \mathrm{~N}$ to the inversion center. It means, that only half of pyrimidine molecules is protonated when considering the whole crystal. The hydrogen atoms bound to N1 and N4 atoms were given an occupancy factor of $1 / 2$.

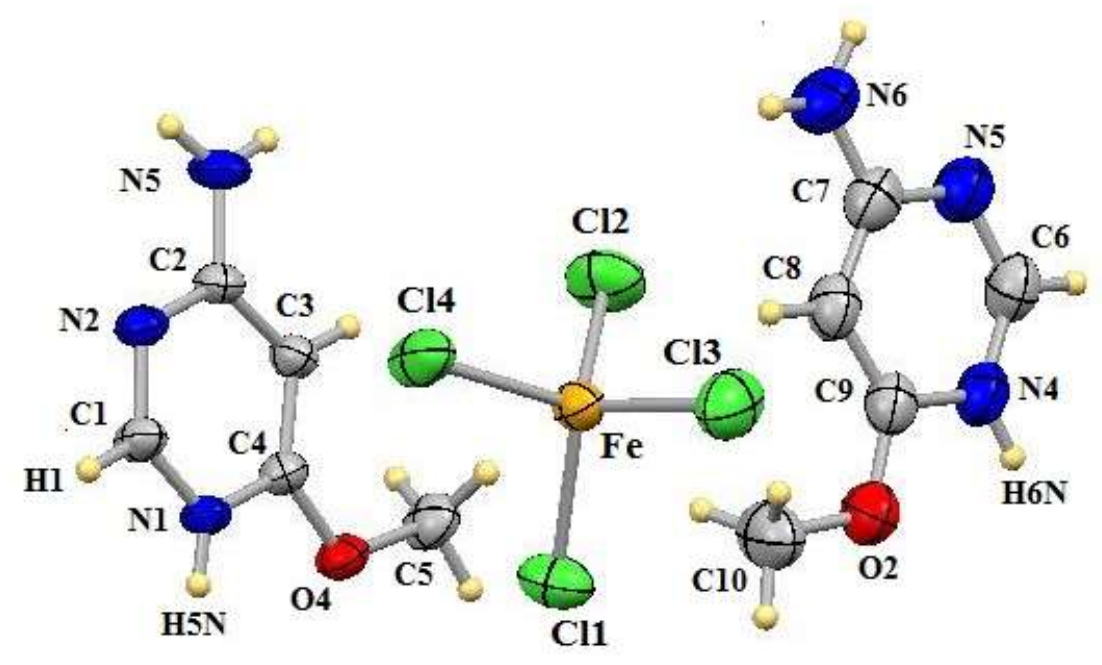

Fig. 1 Molecular structure of the title compound showing the atom-numbering scheme and displacement ellipsoids drawn at the $50 \%$ probability level 
In the atomic arrangement of the title compound, the iron (III) atom is surrounded by four chlorine anions. The bond distances around the iron atom, reported in Table 2, are consistent with the literature [18]. The values of the $\mathrm{Cl}-\mathrm{Fe}-\mathrm{Cl}$ bond angles, which vary between $108.54(4)^{\circ}$ and $111.02(5)^{\circ}$, indicate that the coordination sphere geometry around the $\mathrm{Fe}(\mathrm{III})$ metal cation can be considered as slightly distorted tetrahedral, in agreement with the geometry of $\left(\mathrm{CSH}_{6} \mathrm{~N}\right)\left[\mathrm{FeCl}_{4}\right][19]$ and $\left(\mathrm{NEt}_{4}\right)\left[\mathrm{FeCl}_{4}\right][20]$.

Table 2 Selected bond distances and angles $\left(\AA,{ }^{\circ}\right)$ in $\left(\mathrm{C}_{5} \mathrm{H}_{7.50} \mathrm{~N}_{3} \mathrm{O}\right)_{2}\left[\mathrm{FeCl}_{4}\right]$

\begin{tabular}{|llll|}
\hline Fe-Cl1 & $2.1908(9)$ & Cl4-Fe1-Cl2 & $108.54(4)$ \\
Fe- C12 & $2.1815(9)$ & Cl4-Fe1-Cl5 & $111.02(5)$ \\
Fe-C13 & $2.1840(10)$ & $\mathrm{C} 2-\mathrm{Fe} 1-\mathrm{Cl} 3$ & $109.03(5)$ \\
$\mathrm{Fe}-\mathrm{Cl} 4$ & $2.1789(8)$ & $\mathrm{C} 14-\mathrm{Fe} 1-\mathrm{Cl} 1$ & $108.50(4)$ \\
$\mathrm{O} 1-\mathrm{C} 4$ & $1.333(3)$ & $\mathrm{C} 2-\mathrm{Fe} 1-\mathrm{Cl} 1$ & $110.64(4)$ \\
$\mathrm{O} 1-\mathrm{C} 5$ & $1.441(3)$ & $\mathrm{C} 13-\mathrm{Fe} 1-\mathrm{Cl} 1$ & $109.12(4)$ \\
$\mathrm{O} 2-\mathrm{C} 9$ & $1.325(4)$ & $\mathrm{C}-\mathrm{O} 2-\mathrm{C} 10$ & $117.2(3)$ \\
$\mathrm{O} 2-\mathrm{C} 10$ & $1.440(4)$ & $\mathrm{C} 1-\mathrm{N} 1-\mathrm{C} 4$ & $117.6(2)$ \\
$\mathrm{N} 1-\mathrm{C} 1$ & $1.326(3)$ & $\mathrm{C} 1-\mathrm{N} 2-\mathrm{C} 2$ & $115.8(2)$ \\
$\mathrm{N} 1-\mathrm{C} 4$ & $1.354(3)$ & $\mathrm{C} 6-\mathrm{N} 4-\mathrm{C} 9$ & $117.9(3)$ \\
$\mathrm{N} 2-\mathrm{C} 1$ & $1.315(3)$ & $\mathrm{C} 6-\mathrm{N} 5-\mathrm{C} 7$ & $115.5(3)$ \\
$\mathrm{N} 2-\mathrm{C} 2$ & $1.365(3)$ & $\mathrm{N} 2-\mathrm{C} 1-\mathrm{N} 1$ & $126.6(2)$ \\
$\mathrm{N} 3-\mathrm{C} 2$ & $1.323(3)$ & $\mathrm{N} 3-\mathrm{C} 2-\mathrm{N} 2$ & $116.6(2)$ \\
$\mathrm{N} 4-\mathrm{C} 6$ & $1.328(5)$ & $\mathrm{C} 4-\mathrm{C} 3-\mathrm{C} 2$ & $117.6(2)$ \\
$\mathrm{C} 2-\mathrm{C} 3$ & $1.397(3)$ & $\mathrm{N} 5-\mathrm{C} 6-\mathrm{N} 4$ & $126.8(3)$ \\
$\mathrm{C} 3-\mathrm{C} 4$ & $1.362(3)$ & $\mathrm{N} 6-\mathrm{C} 7-\mathrm{N} 5$ & $116.5(4)$ \\
$\mathrm{C} 7-\mathrm{C} 8$ & $1.392(5)$ & $\mathrm{C} 9-\mathrm{C} 8-\mathrm{C} 7$ & $117.8(3)$ \\
$\mathrm{C} 8-\mathrm{C} 9$ & $1.367(4)$ & $\mathrm{O} 2-\mathrm{C} 9-\mathrm{N} 4$ & $112.4(3)$ \\
\hline
\end{tabular}

The distances and bond angles describing the organic groups are given in Table 2. An examination of the $\mathrm{C}-\mathrm{NH}_{2}$ bonds shows that in both molecules the $\mathrm{C}-\mathrm{N}$ distance is short for a single bond, but not as well contracted as one could expect for a fully established double bond. This indicates that the N3 and N6 nitrogen atoms of the amino group are probably in $\mathrm{sp}^{2}$

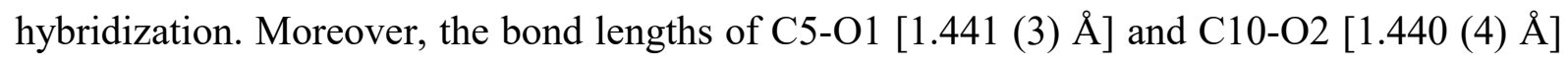
clearly indicate two simple bonds, while the distances C4-O1 [1.332 (2) A] and C9-O2 [1.325 (4) $\AA$ ] are shorter, which is probably due to the donor mesomeric effect of the methoxy group. In the crystal lattice, the isolated $\left[\mathrm{FeCl}_{4}\right]^{-}$tetrahedra form layers parallel to the $(a, b)$ plane at $z=1 / 4(2 n+1)$. The organic cations are inserted between the inorganic layers and 
interact with them through hydrogen bonds with the chloride anions, generated by the amine and the methyl groups as donors (Fig. 2, Table 3). The organic groups, in turn, are linked together by strong N-H...N hydrogen bonds to form chains which consist of an alternation of pyrimidine and pyrimidinium molecules and they develop along the [110] direction (Fig.3). These chains are arranged in planes parallel to $(a, b)$ at $z=1 / 2 n$.

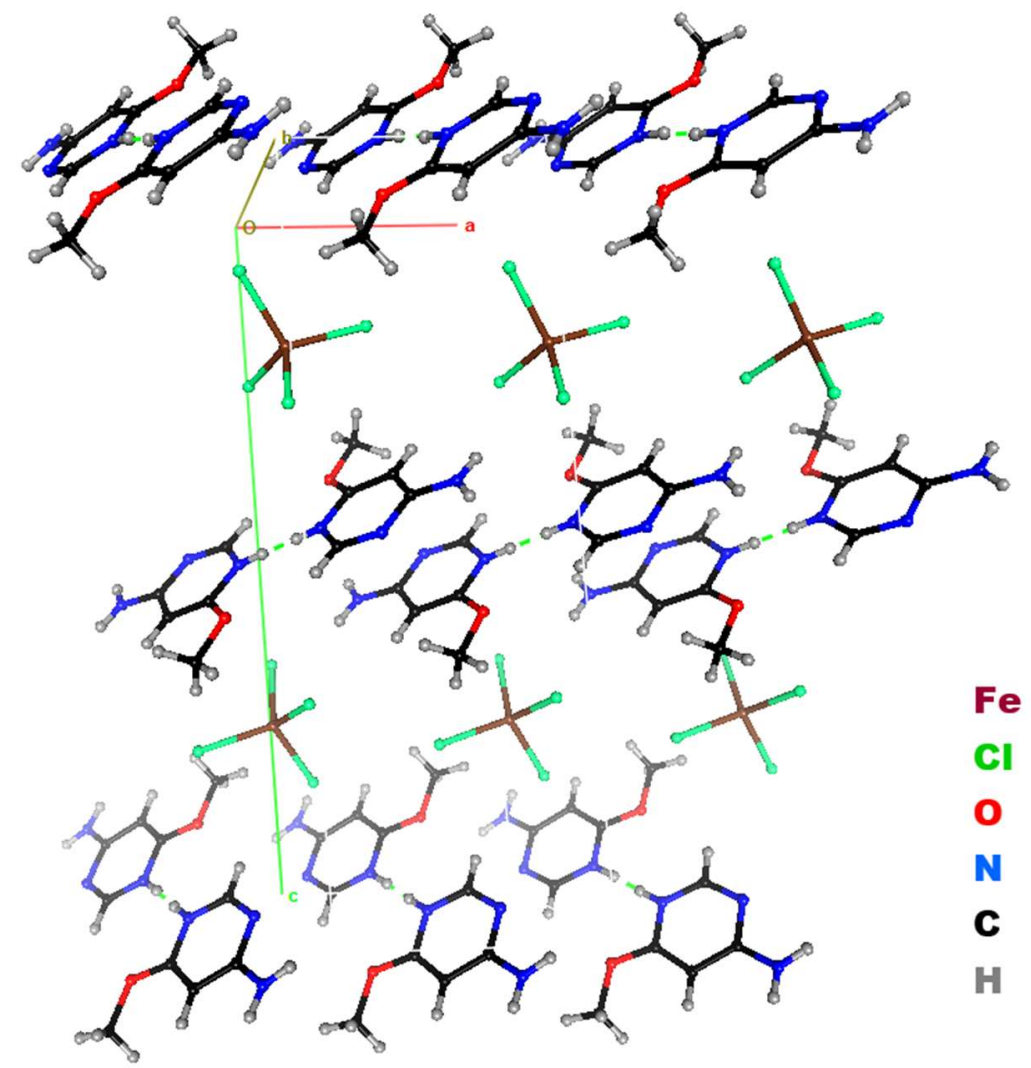

Fig. 2 Crystallographic autostereogram showing the packing arrangement of $\left(\mathrm{C}_{5} \mathrm{H}_{7.50} \mathrm{~N}_{3} \mathrm{O}\right)_{2}\left[\mathrm{FeCl}_{4}\right]$ viewed along $b$-axis. Green dotted lines indicate N-H...N hydrogen bonds

Table 3 Hydrogen-bond geometry $\left(\AA,^{o}\right)$ in $\left(\mathrm{C}_{5} \mathrm{H}_{7.50} \mathrm{~N}_{3} \mathrm{O}\right)_{2}\left[\mathrm{FeCl}_{4}\right]$

\begin{tabular}{lllll}
\hline$D-\mathrm{H} \cdots A$ & $D-\mathrm{H}$ & $\mathrm{H} \cdots A$ & $D \cdots A$ & $D-\mathrm{H} \cdots A$ \\
\hline $\mathrm{C} 1-\mathrm{H} 1 \cdots \mathrm{Cl} 4^{\mathrm{i}}$ & 0.93 & 2.84 & $3.623(3)$ & 143 \\
$\mathrm{C} 3-\mathrm{H} 4 \cdots \mathrm{Cl} 1^{\mathrm{ii}}$ & 0.93 & 2.95 & $3.780(2)$ & 149 \\
$\mathrm{C} 5-\mathrm{H} 6 B \cdots \mathrm{Cl} 4^{\mathrm{iii}}$ & 0.96 & 2.91 & $3.707(3)$ & 141 \\
$\mathrm{C} 8-\mathrm{H} 10 \cdots \mathrm{Cl} 2^{\mathrm{iv}}$ & 0.93 & 2.80 & $3.694(3)$ & 163 \\
$\mathrm{C} 10-\mathrm{H} 12 B \cdots \mathrm{Cl}{ }^{\mathrm{v}}$ & 0.96 & 2.93 & $3.822(4)$ & 155 \\
$\mathrm{~N} 3-\mathrm{H} 1 N \cdots \mathrm{Cl} 1^{\mathrm{ii}}$ & $0.86(2)$ & $2.88(2)$ & $3.688(3)$ & $159(3)$ \\
\hline
\end{tabular}




\begin{tabular}{lllll}
\hline $\mathrm{N} 3-\mathrm{H} 2 N \cdots \mathrm{N} 2^{\mathrm{vi}}$ & $0.87(2)$ & $2.20(2)$ & $3.069(3)$ & $175(3)$ \\
$\mathrm{N} 6-\mathrm{H} 3 N \cdots \mathrm{Cl} 3^{\mathrm{vii}}$ & $0.87(2)$ & $2.77(3)$ & $3.368(4)$ & $127(3)$ \\
$\mathrm{N} 6-\mathrm{H} 4 N \cdots \mathrm{N} 5^{\text {viii }}$ & $0.88(2)$ & $2.14(2)$ & $3.018(5)$ & $174(4)$ \\
$\mathrm{N} 1-\mathrm{H} 5 N^{\cdots} \cdots \mathrm{N} 1^{\mathrm{ix}}$ & $0.81(4)$ & $1.89(4)$ & $2.695(4)$ & $176(5)$
\end{tabular}

Symmetry codes: (i)- $\mathrm{x},-\mathrm{y},-\mathrm{z}+1$; (ii) $\mathrm{x}-1, \mathrm{y}, \mathrm{z}$; (iii) $\mathrm{x}, \mathrm{y}+1, \mathrm{z} ;$ (iv) $\mathrm{x}+1, \mathrm{y}-1, \mathrm{z} ;$ (v) $\mathrm{x}+1, \mathrm{y}, \mathrm{z} ;(\mathrm{vi})-\mathrm{x}-$ $1,-y,-z+1,($ vii) $x, y-1, z ;($ viii $)-x,-y-1,-z+2 ;($ ix $)-x,-y+1,-z+1$.

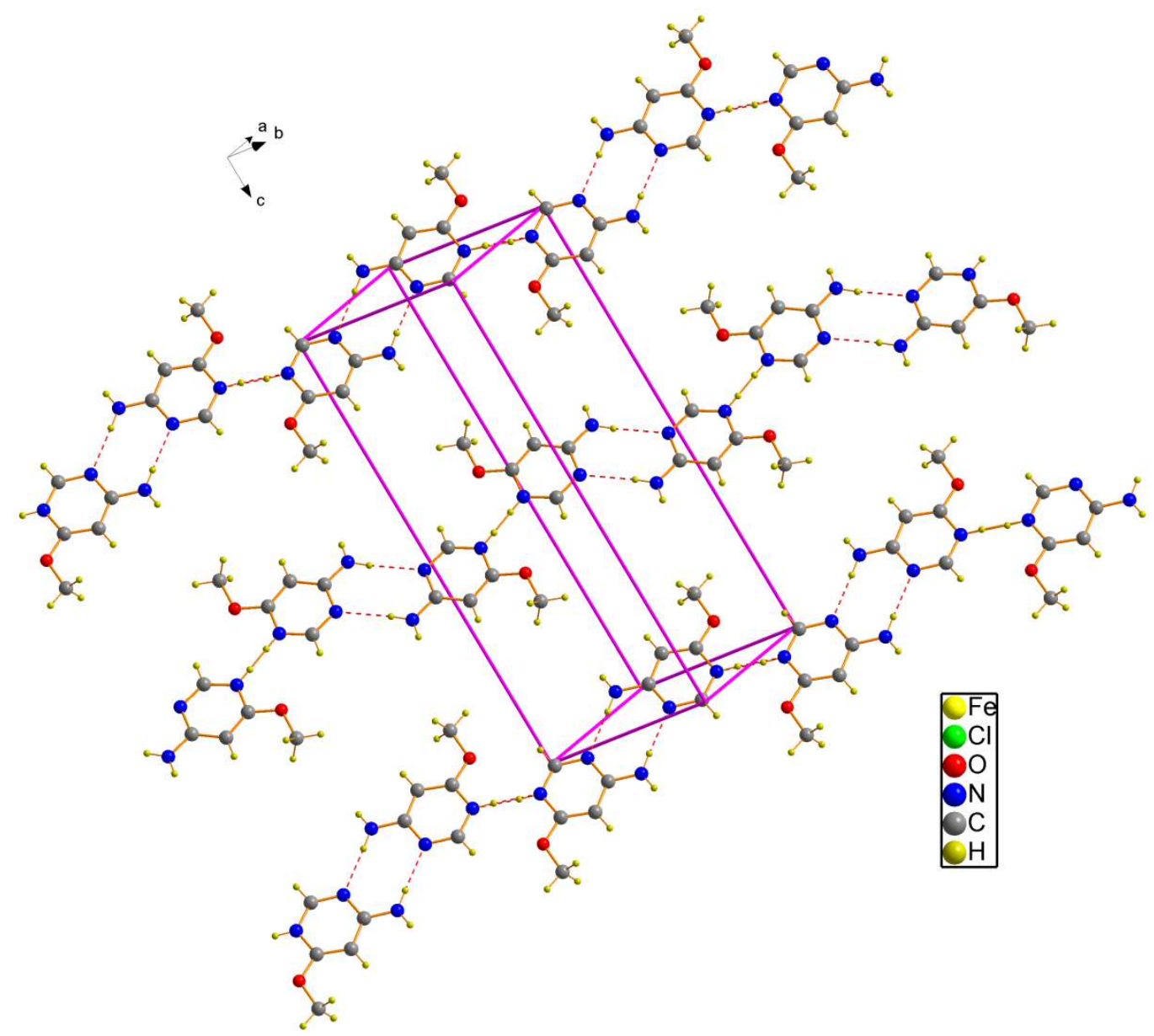

Fig. 3 View of 1D zigzag chain $\left[\left(\mathrm{C}_{5} \mathrm{H}_{7.50} \mathrm{~N}_{3} \mathrm{O}\right)_{2}\right]_{\mathrm{n}}$ along the $[110]$ direction

\section{Hirshfeld surface analysis}

Analysis of intermolecular interactions on the Hirshfeld surface gives major insights into the crystal packing. The Hirshfeld surface was computed with the MoProViewer software [21]. The enrichment ratios $[22,23]$ of contacts between the different chemical species were computed in order to highlight which interactions are statistically favored in the crystal packing. 
The chemical nature of contacts and their enrichment in the crystal structure are shown in Table 4.

For the Hirshfeld surface analysis, a dimer of the asymmetric unit was generated as the two half occupied hydrogen atoms were deleted in half of the organic cations. To obtain an integral Hirshfeld surface around each moiety, entities not in contact with each other were generated in the crystal packing. The $\mathrm{FeCl}_{4}{ }^{-}$anion was considered as an integral moiety. The same dimer was used to compute the fingerprint plots with program CrystalExplorer [24] (Fig. 4).

Table 4 Nature of intermolecular contacts on the Hirshfeld surface by chemical types. The second row shows the chemical content on the Hirshfeld surface. The \% of contact types between chemical species is then given followed by their enrichment ratio. The major contacts as well as the most enriched ones are highlighted in bold. The hydrophobic Hc atoms bound to carbon were distinguished from the more polar Ho water hydrogen atoms.

\begin{tabular}{|c|ccccccc|}
\hline atom & $\mathrm{Fe}$ & $\mathrm{Cl}$ & $\mathrm{O}$ & $\mathrm{Hn}$ & $\mathrm{N}$ & $\mathrm{Hc}$ & $\mathrm{C}$ \\
\hline \% surf & 4.2 & 28.1 & 3.9 & 12.9 & 10.5 & 24.7 & 15.8 \\
\hline $\mathrm{Fe}$ & 0.0 & 1.1 & 0.0 & 1.0 & 0.2 & 4.1 & 2.2 \\
$\mathrm{Cl}$ & & 4.8 & 1.9 & $\mathbf{8 . 5}$ & 1.6 & $\mathbf{2 5 . 7}$ & $\mathbf{1 0 . 1}$ \\
$\mathrm{O}$ & & & 0.0 & 1.3 & 0.9 & 3.1 & 0.3 \\
$\mathrm{Hn}$ & & & & 1.1 & $\mathbf{9 . 6}$ & 1.6 & 1.6 \\
$\mathrm{~N}$ & $\%$ & contacts & & & 0.8 & 3.7 & 3.1 \\
$\mathrm{Hc}$ & & & & & & 2.7 & 4.2 \\
$\mathrm{C}$ & & & & & & & 4.9 \\
\hline $\mathrm{Fe}$ & 0.00 & 0.44 & 0.01 & 0.93 & 0.24 & 2.0 & 1.6 \\
$\mathrm{Cl}$ & & 0.56 & 0.86 & 1.13 & 0.26 & $\mathbf{1 . 8}$ & 1.10 \\
$\mathrm{O}$ & & & 0.00 & $\mathbf{1 . 3}$ & 1.2 & $\mathbf{1 . 7}$ & 0.25 \\
$\mathrm{Hn}$ & & & & 0.65 & $\mathbf{3 . 6}$ & 0.26 & 0.40 \\
$\mathrm{~N}$ & & \multirow{2}{*}{ enrich ment } & & 0.71 & 0.76 & 0.96 \\
$\mathrm{Hc}$ & & & & & & 0.48 & 0.56 \\
$\mathrm{C}$ & & & & & & & $\mathbf{2 . 0}$ \\
\hline
\end{tabular}

The Hirshfeld surface analysis of the molecule shows that $\mathrm{H} . . . \mathrm{Cl}$ and $\mathrm{N}$...H interactions exhibit the most significant contributions (Figs. $4 \mathrm{a}$ and $4 \mathrm{~b}$, respectively). There are indeed seven $\mathrm{H} \ldots \mathrm{Cl}$ 
hydrogen bonds and three N...H interactions in the crystal structure (Table 3). Globally the $\mathrm{H} . . . \mathrm{Cl}$ and $\mathrm{N} . . . \mathrm{H}$ interactions constitute as much as $47.5 \%$ of the contact surface; the enriched $\mathrm{N}$...H-N strong H-bonds and $\mathrm{Cl}$...H-C weak H-bonds are the driving force in the crystal packing stabilization.

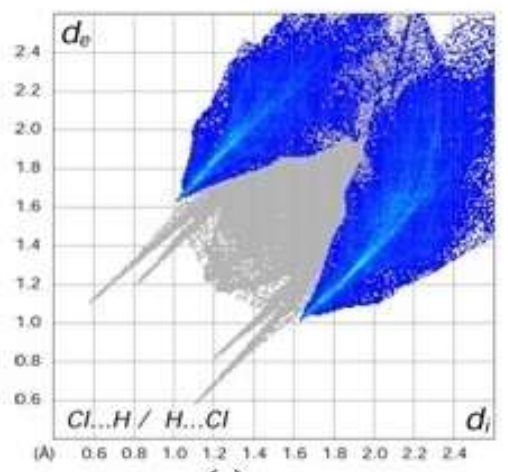

(a)

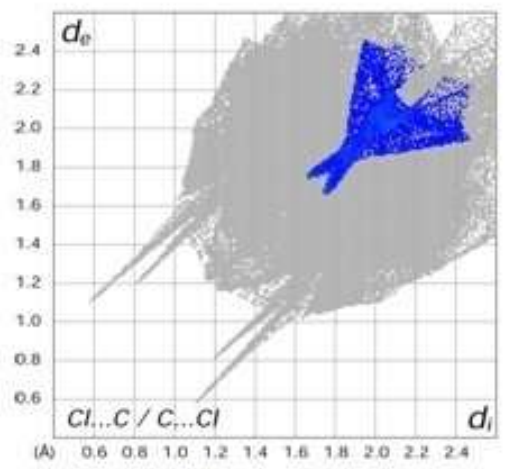

(c)

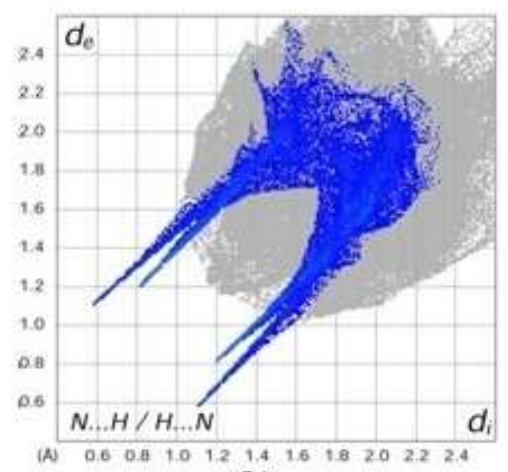

(b)

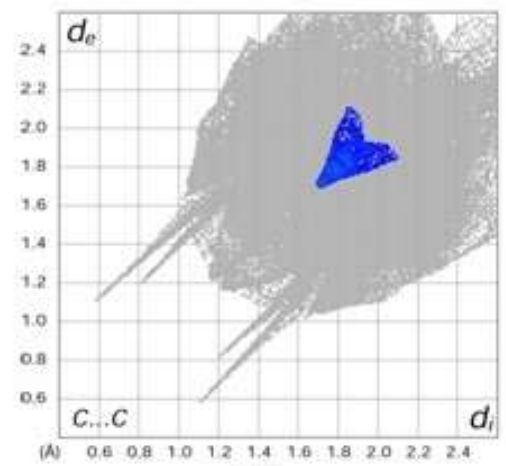

(d)

Fig. 4 Fingerprint plots of contacts in $\left(\mathrm{C}_{5} \mathrm{H}_{7.50} \mathrm{~N}_{3} \mathrm{O}\right)_{2}\left[\mathrm{FeCl}_{4}\right]$

Among polar atoms, the chloride anions contribute at $28 \%$ to the largest surface followed by hydrogen $\mathrm{Hn}$ and nitrogen atoms (Table 4). The weak hydrogen bonds $\mathrm{C}^{-} \mathrm{H}^{\delta+} \ldots \mathrm{Cl}^{-}$are the major contact type, representing as much as one quarter of the surface, as these two chemical species are the most abundant and the contact is enriched at $E=1.8$.

The strong hydrogen bonds $\mathrm{Cl}^{-} \ldots \mathrm{Hn}$ and $\mathrm{N} . . \mathrm{Hn}$ are significantly abundant, just below $10 \%$, the latter being the most enriched contact of the crystal packing $(E=3.6)$. 
Each of the two independent organic cations forms a stacking interaction with itself via an inversion centre. This results in significant over-represented C...C contacts. All self contacts are generally avoided, excepted for C...C.

Globally, fourty percent of the Hirshfeld surface can be considered as hydrophobic (atoms $\mathrm{C}$ and $\mathrm{Hc}$ ) and sixty percent as hydrophilic (polar). The contacts between hydrophobic atoms represent only $12 \%$ of the surface and are under-represented with a global enrichment ratio $E=0.72$. Contacts between charged atoms are also under-represented at $E=0.90$. On the other hand, the cross contacts between polar and hydrophobic atoms represent more than $55 \%$ of the surface and are enriched at $E=1.15$. This behavior in hydrid organic/inorganic crystalline materials is unusual but if the interactions within the $\mathrm{FeCl}_{4}$ complex had been counted, polar...polar interactions would have been better represented. The over-represented crosscontacts are due, in part, to the favored weak hydrogen bonds $\mathrm{Cl}^{-} \ldots \mathrm{Hc}$ and $\mathrm{N}$...Hc. For the methoxy oxygen atom, the interactions with $\mathrm{Hc}$ are also more favored than with $\mathrm{Hn}$ atoms. The $\mathrm{FeCl}_{4}$ anions form layers parallel to the $(\mathbf{a}, \mathbf{b})$ plane and the slightly electropositive methyl groups (of both independent cations) are inserted between adjacent anions.

The Hirshfeld surface was also computed around the four chloride anions. The four $\mathrm{Cl}^{-}$ atoms show similar contact types with a correlation in the range $0.87-0.984$.

Globally, the two independent organic cations display very similar interactions, the correlation between the proportions $C_{\mathrm{xy}}$ of contact types reaches $r=97 \%$, while for the enrichment ratios, the correlation is $r=88 \%$. The different contacts types are however not occurring on the same locations of the two independent cations, as can be seen in Fig. 5 . 

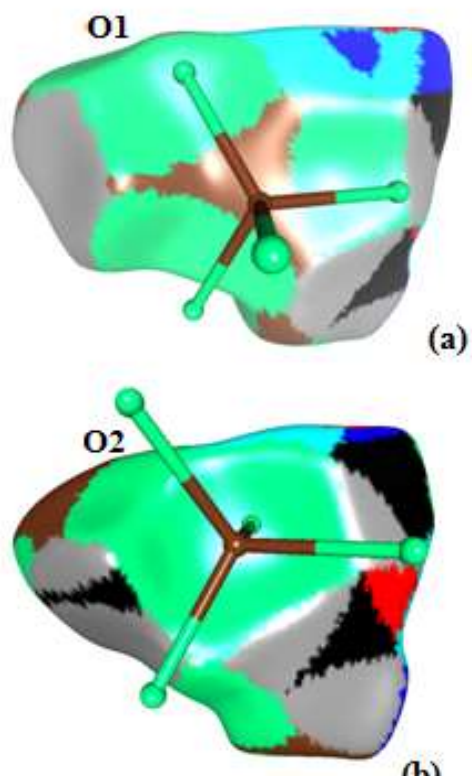

(b)

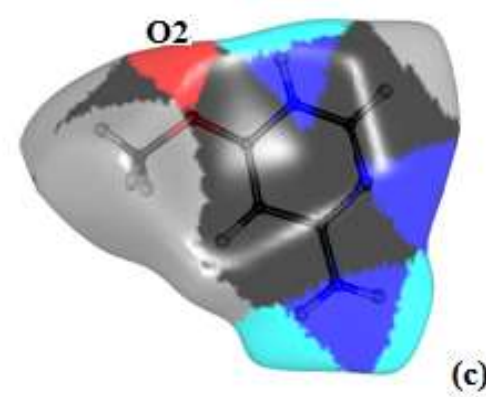

Fig. 5 View of the Hirshfeld surface of the two organic cations, on the side interacting with the $\mathrm{FeCl}_{4}$ anion. (a) and (b) are colored according to the exterior interacting atom (c). View of the semitransparent surface, with inner atom coloring showing the molecule orientation. The O1 or $\mathrm{O} 2$ oxygen atom is marked to identify the molecule. Hc: light grey, $\mathrm{C}$ : black, N: blue, O: red, Hn: light blue. Fe: dark red, $\mathrm{Cl}$ : green 


\section{Quantum mechanical study}

Quantum computation was performed from the crystal data with the DFT method. The HOMO and LUMO of the title compound are shown in Fig. 6. It is clear that the HOMO is localized on one of two organic cations, while the LUMO is located on the $\left[\mathrm{FeCl}_{4}\right]^{-}$anion. The gap energy value between the HOMO and LUMO orbitals in the title compound is relatively low, $E_{g}=\left(E_{L U M O}-E_{H O M O}\right)=1.15 \mathrm{eV}$, proving that some electrons can pass from the valence band to the conduction band by application of an external electric field. Thus, the synthesized material has a semiconductor behavior. The energy distributions of the different orbitals are given in Fig. 7.

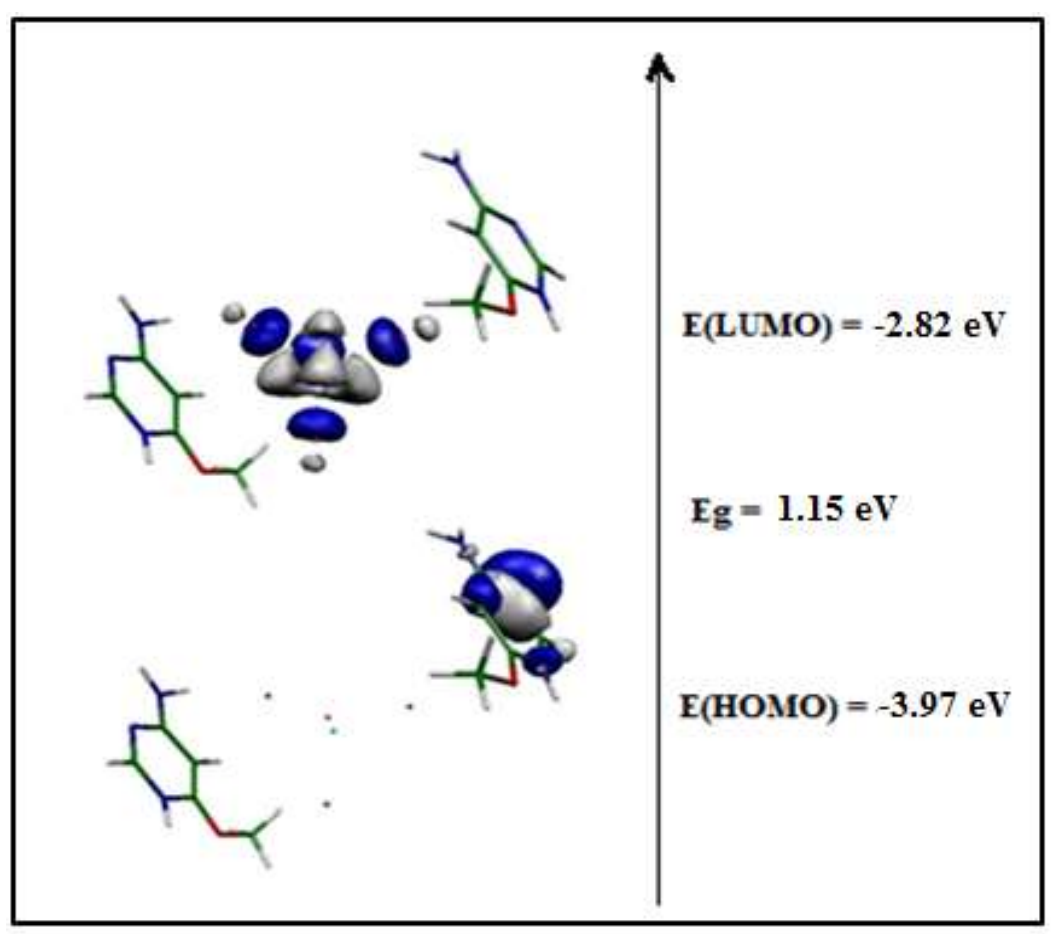

Fig. 6 Frontier orbitals of $\left(\mathrm{C}_{5} \mathrm{H}_{7.50} \mathrm{~N}_{3} \mathrm{O}\right)_{2}\left[\mathrm{FeCl}_{4}\right]$ 


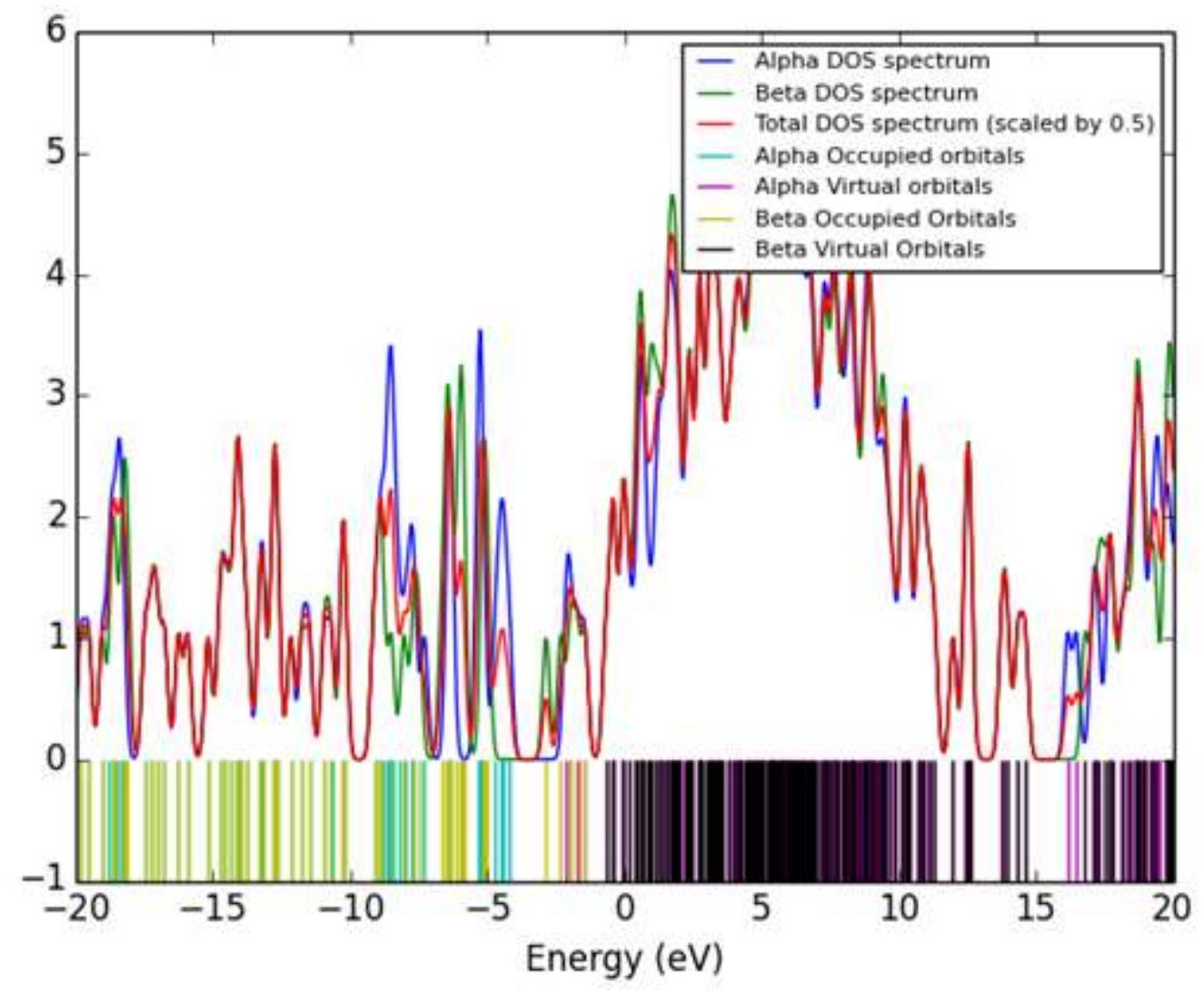

Fig. 7 Energy distribution of the different orbitals of $\left(\mathrm{C}_{5} \mathrm{H}_{7.50} \mathrm{~N}_{3} \mathrm{O}\right)_{2}\left[\mathrm{FeCl}_{4}\right]$ 


\section{Mulliken charges and Mulliken spin densities}

The DFT calculations give also access to Mulliken charges and Mulliken spin densities

(Tables 5 and 6). The numbering of atoms is as follows:

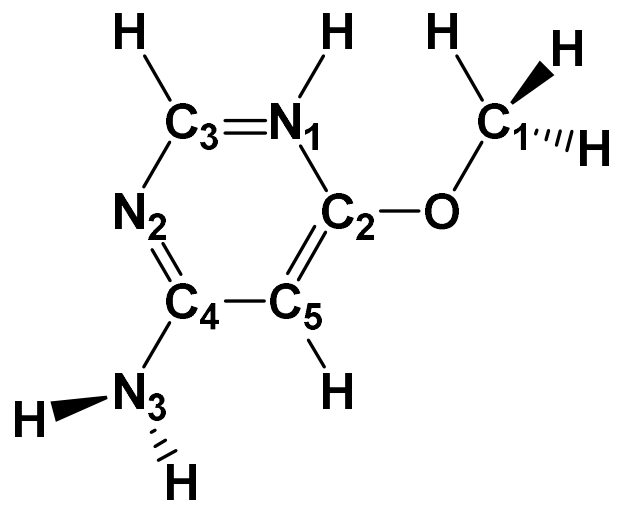

Table 5 Mulliken charges for the title compound

\begin{tabular}{|c|c|c|c|c|}
\hline $\mathrm{Fe}$ & -0.568576 & & & \\
\hline $\mathrm{Cl}$ & -0.351097 & -0.339774 & -0.342693 & -0.066731 \\
\hline \multicolumn{5}{|c|}{ Sum of FeCl charges : -1.67} \\
\hline $\mathrm{C} 1$ & -0.397632 & -0.368702 & & \\
\hline $\mathrm{H}(\mathrm{C} 1)$ & 0.195627 & 0.206940 & & \\
& 0.229088 & 0.231072 & & \\
\hline $\mathrm{C} 2$ & 0.299917 & 0.269119 & & \\
\hline $\mathrm{C} 3$ & 0.251628 & -0.196193 & & \\
\hline $\mathrm{H}(\mathrm{C} 3)$ & 0.107606 & 0.097795 & & \\
\hline $\mathrm{C} 4$ & 0.199613 & 0.215400 & & \\
\hline $\mathrm{C} 5$ & -0.050021 & 0.216580 & & \\
\hline $\mathrm{H}(\mathrm{C} 5)$ & 0.240249 & 0.209922 & & \\
\hline $\mathrm{O}$ & -0.299674 & -0.28467059 & & \\
\hline $\mathrm{N} 1$ & -0.379741 & -0.375571 & & \\
\hline $\mathrm{H}(\mathrm{N} 1)$ & 0.462000 & 0.463488 & & \\
\hline $\mathrm{N} 2$ & -0.229319 & -0.230732 & & \\
\hline $\mathrm{N} 3$ & -0.747691 & -0.768472 & & \\
\hline $\mathrm{H}(\mathrm{N} 3)$ & 0.419477 & 0.405115 & & \\
& 0.426170 & 0.427813 & & \\
\hline Sum of & +0.941 & +0.727 & & \\
ligand & & & & \\
charges & & & & \\
& & & & \\
\hline
\end{tabular}


Table 6 Mulliken spin densities for the title compound

\begin{tabular}{|c|c|c|l|l|}
\hline $\mathrm{Fe}$ & 3.564672 & & & \\
\hline $\mathrm{Cl}$ & 0.134318 & 0.129960 & 0.132276 & 0.137988 \\
\hline $\mathrm{C} 1$ & 0.004704 & -0.001021 & & \\
\hline $\mathrm{H}(\mathrm{C} 1)$ & 0.000108 & -0.000095 & & \\
& -0.000030 & -0.000001 & & \\
& -0.000380 & 0.000098 & & \\
\hline $\mathrm{C} 2$ & -0.043301 & -0.002435 & & \\
\hline $\mathrm{C} 3$ & 0.006052 & -0.063474 & & \\
\hline $\mathrm{H}(\mathrm{C} 3)$ & 0.000101 & 0.003921 & & \\
\hline $\mathrm{C} 4$ & -0.011103 & -0.032509 & & \\
\hline $\mathrm{C} 5$ & 0.033472 & -0.004123 & & \\
\hline $\mathrm{H}(\mathrm{C} 5)$ & 0.000078 & 0.000518 & & \\
\hline $\mathrm{O}$ & 0.000884 & -0.000024 & & \\
\hline $\mathrm{N} 1$ & 0.000091 & 0.001320 & & \\
\hline $\mathrm{H}(\mathrm{N} 1)$ & 0.000157 & 0.000209 & & \\
\hline $\mathrm{N} 2$ & 0.000496 & 0.015133 & & \\
\hline $\mathrm{N} 3$ & 0.000962 & 0.007264 & & \\
\hline $\mathrm{H}(\mathrm{N} 3)$ & 0.000008 & -0.000063 & & \\
& 0.000003 & 0.000216 & & \\
\hline
\end{tabular}

The data gathered in Table 5 show that, in the $\left[\mathrm{FeCl}_{4}\right]^{-}$anion, one chlorine atoms has an atomic charge distribution of -0.0667 a.u, very different from the three others, which vary between -0.3397 and -0.3510 a.u. The sum of charges of the tetrachloroferrate (III) complex is -1.67 a.u. For the ligands, the most important feature is that the $\mathrm{C} 2$ and $\mathrm{C} 5$ carbons have very different charges, these charges compensating each other. The sum of charges of the two ligands is $0.941+0.727=+1.668$ a.u, which equilibrate the negative charge of $\left[\mathrm{FeCl}_{4}\right]^{-}$.

The results of Mulliken spin densities given in Table 6 show, as expected, that the atomic densities of spin are localized on the iron and a little on the chlorine atoms linked to it.

\section{Molecular electrostatic potential}

The molecular electrostatic potential (MEP) is used to predict the molecular reactive behavior towards electrophilic and nucleophilic attack and defined electrophile (electron- 
deficient positively charged species) and nucleophile (an electron rich, negatively charged species) sites. The negative regions of the MEP which represent high electron density appear in red and are related to the electrophilic reactivity while the positive (blue) regions are related to nucleophilic reactivity. As it can be seen on Fig. 8, the red region is located around the $\mathrm{FeCl}_{4}^{-}$ anion which can be considered as electrophilic, while the positive region is localized on the organic cation which will be the reactive sites for nucleophilic attack.

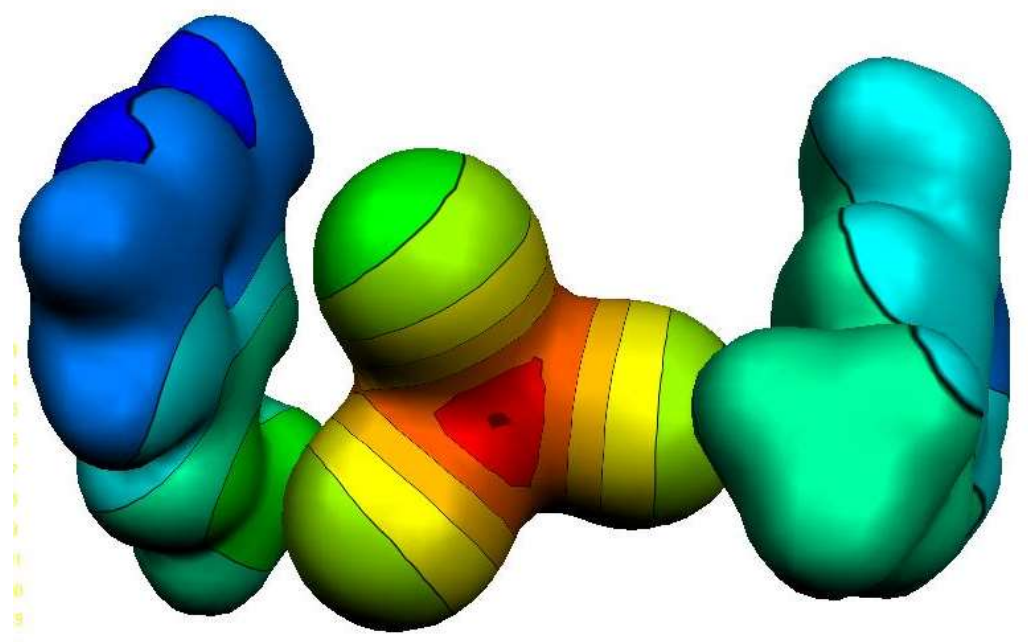

Fig. 8 Molecular Electrostatic Potential maps of $\left(\mathrm{C}_{5} \mathrm{H}_{7.50} \mathrm{~N}_{3} \mathrm{O}\right)_{2}\left[\mathrm{FeCl}_{4}\right]$

\section{Vibrational study}

Infrared absorption spectroscopy was used to verify the functional groups present in the crystal and to investigate their vibrational behavior in the solid state. The IR spectrum of the title crystalline compound is shown in Fig. 9-a. The characteristic vibrational modes of this complex can be compared to those of similar materials [25-27]. In the high-frequency region, the very large band spreading between 3600 and $2800 \mathrm{~cm}^{-1}$ corresponds to the valence vibrations of C-H and N-H groups interconnected by a system of hydrogen bonds in the crystal [28]. The bands observed in the 1600 to $1050 \mathrm{~cm}^{-1}$ region can be assigned to the $\mathrm{N}-\mathrm{H}$ and $\mathrm{C}-\mathrm{H}$ bending vibrations and to the valence vibrations of $\mathrm{C}=\mathrm{C}, \mathrm{C}-\mathrm{C}, \mathrm{C}-\mathrm{N}$ and $\mathrm{C}-\mathrm{N}$ groups [29]. The 
observed bands in the range $1000-600 \mathrm{~cm}^{-1}$ can be attributed to the out of plane bending modes of skeleton of amino-pyrimidine rings [30].

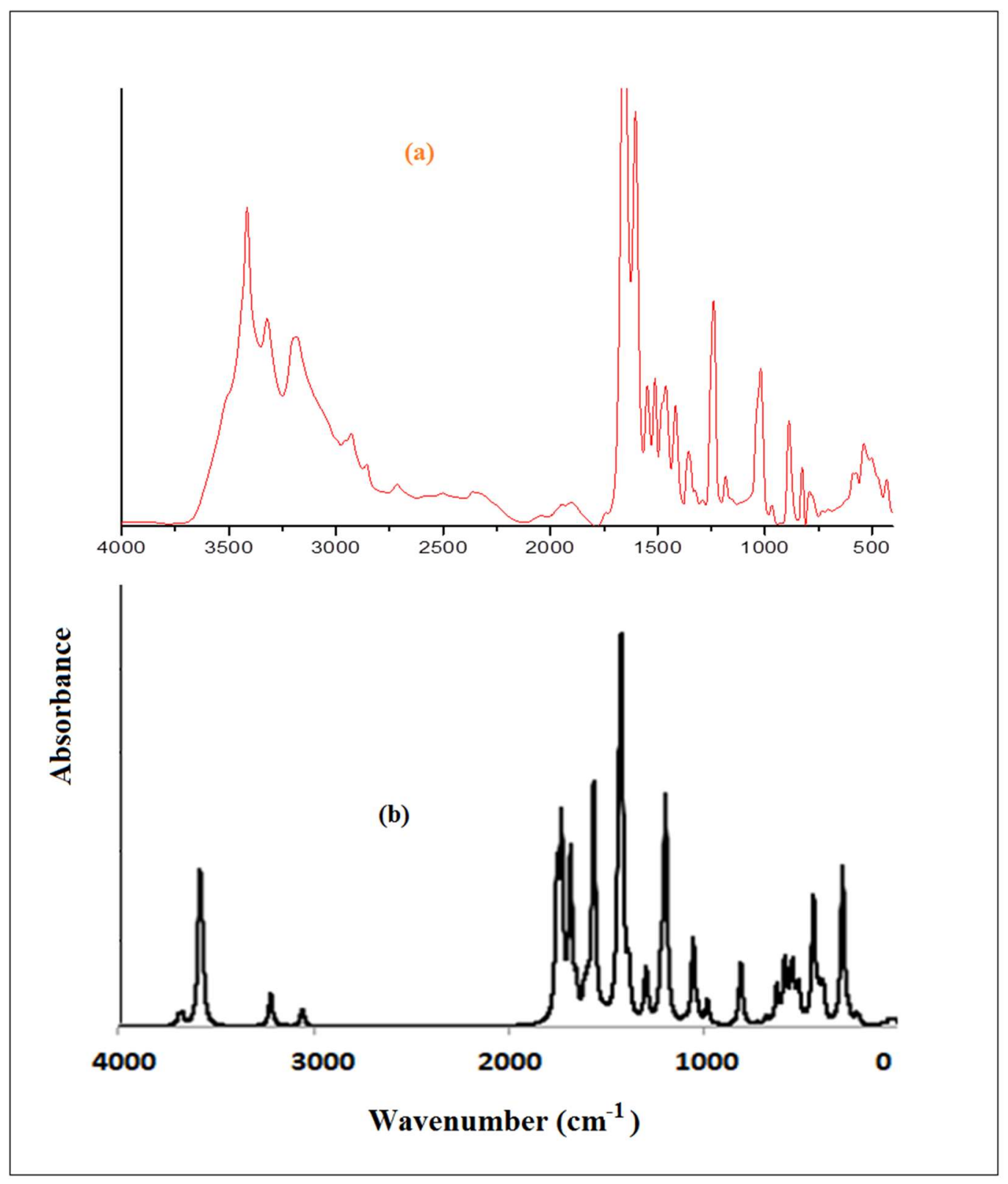

Fig. 8 Molecular Electrostatic Potential maps of $\left(\mathrm{C}_{5} \mathrm{H}_{7.50} \mathrm{~N}_{3} \mathrm{O}\right)_{2}\left[\mathrm{FeCl}_{4}\right]$

The infrared spectrum of $\left(\mathrm{C}_{5} \mathrm{H}_{7.50} \mathrm{~N}_{3} \mathrm{O}\right)_{2}\left[\mathrm{FeCl}_{4}\right]$ was also calculated by DFT. The resulting IR spectrum is shown on Fig. 9-b and is very similar to the experimental one. A close agreement between the experimental and theoretical wave numbers is mostly achieved as shown in Fig. 
10. Thus, the precision is well-sufficient to assign the experimental frequencies and to confirm the attributions proposed above.

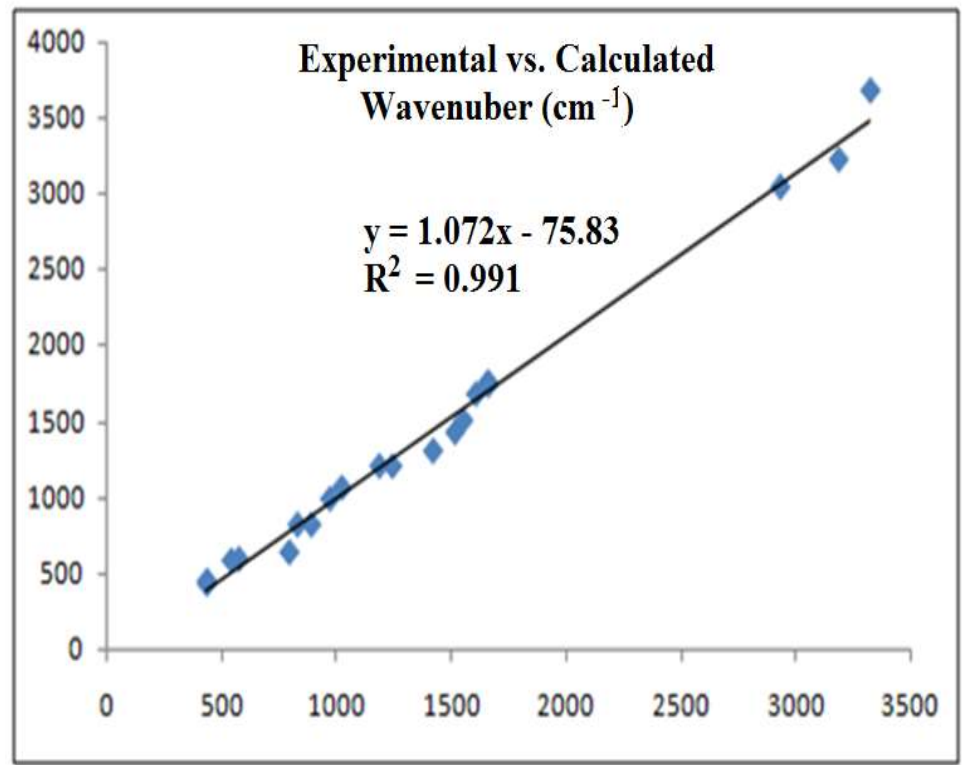

Fig. 9 Infrared absorption spectrum experimental (a) and calculated (b) of $\left(\mathrm{C}_{5} \mathrm{H}_{7.50} \mathrm{~N}_{3} \mathrm{O}\right)_{2}\left[\mathrm{FeCl}_{4}\right]$

\section{Conclusion}

We have reported synthesis, crystal structure, physicochemical study and the Hirshfeld surface analysis of new tetrachloro-ferrate(III) salt. The results of single crystal X-ray diffraction analysis of this compound show that the tetrachloro-ferrate (III) anions form layers parallel to the $(\mathbf{a}, \mathbf{b})$ plane between which the organic cations are inserted. After formation of the $\mathrm{FeCl}_{4}$ anion, the crystal structure is mainly stabilized by $\mathrm{N}-\mathrm{H} . . . \mathrm{Cl}, \mathrm{N}-\mathrm{H} . . . \mathrm{N}$ and $\mathrm{C}-\mathrm{H} . . . \mathrm{Cl}$ hydrogen bonds and shows also significant pyrimidinium cycle stacking (C...C contacts). DFT calculations allow the attribution of the experimental IR bands. Frontier molecular orbitals study shows a low bond gap $(1.15 \mathrm{eV})$ confirming a semiconductor character for the reported compound. 


\section{Supplementary data}

Crystallographic data for the structural analysis have been deposited at the Cambridge Crystallographic Data Centre, CCDC No 1922466. These data can be obtained free of charge via http://www.ccdc.cam.ac.uk/conts/retrieving.html, or from the CCDC, 12 Union Road, Cambridge, CB2 1EZ, UK: fax: (+44) 01223-336-033; e-mail: deposit@ccdc.cam.ac.

\section{References}

1. A. Nicolenco, N. Tsyntsaru, J. Fornell, E. Pellicer, J. Reklaitis, D. Baltrunas, H. Cesiulis, J. Sort, Mater. Design 139, 429 (2018)

2. T. Trindade, P.OBrian, N. L. Pickett, Chem. Mater. 13, 3843 (2001)

3. A.N. Shipway, E. Katz, I. Willner, Chem. Phys. Chem. 1, 18 (2000)

4. M.C. Daniel, D. Astrus, Chem. Rev. 104, 293 (2004)

5. D. D. Schwert, N. Richardson, G. Ji, B. Raduchel, W.Ebert, P. E. Heffner, R. Keck, J. A. Davies, Med. Chem. 48, 7482 (2005)

6. M. H. Torre, D. Gambino, J. Araujo, H. Cerecetto, M. Gonzalez, M. L. Azqueta, A. L. Cerain, A. M. Vega, U. Abram, A.J. CostaFilho, J. Eur. Med. Chem. 40, 473 (2005)

7. D.R. Rechardson, P.V. Bernhardt, J. Biol, Inorg. Chem. 4, 166 (1999)

8. M. Brookhart, B.L. Small, Macromol. 32, 2120 (1999)

9. N. Flavia, L. Angela, M. Giancarlo, P. Carlo, P. Vincenzo, C. Genevieve, B. Pierrette, M. Daniel, J. Biol, Inorg. Chem. 3, 671 (1998)

10. E. Pedreno, AJ. Lopez-Contreras, A. Cremades, R. Penaflel, Bioinorg. Chem. 99, 2074 (2005)

11. R.H. Blessing, Acta Crystallogr. A 51, 33 (1995)

12. A. Altomare, M.C. Burla, M. Camalli, G. Cascarano, C. Giacovazzo, A. Guagliardi, A.G. Moliterni, G. Polidori, R. Spagna, J. Appl. Crystallogr. 32, 115 (1999) 
13. G.M. Sheldrick, SHELXL97, Program for Crystal Structure Refinement, (University of Gottingen, Gottingen, Germany, 1997)

14. L.J. Farrugia, J. Appl. Crystallogr. 32, 837 (1999)

15. K. Brandenburg, Diamond Version 2.0 Impact GbR, (Bonn., Germany, 1998)

16. C.F. Macrae, I.J. Bruno, J.A. Chisholm, P.R. Edgington, P. McCabe, E. Pidcock, L. Rodriguez-Monge, R. Taylor, J. van de Streek, P.A. Wood, J. Appl. Crystallogr. 41, 466 (2008)

17. M. J. Frisch, G. W. Trucks, H. B. Schlegel, G. E. Scuseria, M. A. Robb, J. R. Cheeseman, G. Scalmani, V. Barone, B. Mennucci, G. A. Petersson, H. Nakatsuji, M. Caricato, X. Li, H. P. Hratchian, A. F. Izmaylov, J. Bloino, G. Zheng, J. L. Sonnenberg, M. Hada, M. Ehara, K. Toyota, R. Fukuda, J. Hasegawa, M. Ishida, T. Nakajima, Y. Honda, O. Kitao, H. Nakai, T. Vreven, J. A. Montgomery, Jr., J. E. Peralta, F. Ogliaro, M. Bearpark, J. J. Heyd, E. Brothers, K. N. Kudin, V. N. Staroverov, R. Kobayashi, J. Normand, K. Raghavachari, A. Rendell, J. C. Burant, S. S. Iyengar, J. Tomasi, M. Cossi, N. Rega, J. M. Millam, M. Klene, J. E. Knox, J. B. Cross, V. Bakken, C. Adamo, J. Jaramillo, R. Gomperts, R. E. Stratmann, O. Yazyev, A. J. Austin, R. Cammi, C. Pomelli, J. W. Ochterski, R. L. Martin, K. Morokuma, V. G. Zakrzewski, G. A. Voth, P. Salvador, J. J. Dannenberg, S. Dapprich, A. D. Daniels, O. Farkas, J. B. Foresman, J. V. Ortiz, J. Cioslowski, and D. J. Fox, (Gaussian, Inc., Wallingford CT, 2009)

18. A. G. Bottomley, A. M. Carter, L. M. Engelhardt, F. J. Lincoln, J. M. Patrick, A. H. White, Aust. J. Chem. 37, 871 (1984)

19. B. James, M. Millikan, M. Mackay, Inorg. Chim. Acta 64, 55 (1982)

20. M. Smith,Y. Xiao, H. Wang, S. George, D. Coucouvanis, M. Koutmos, W. Sturhahn, E. Alp, J. Zhao, S. Cramer, Inorg. Chem. 44 (2005) 5562-5570

21. B. Guillot, E. Enrique, L. Huder, C. Jelsch, Acta Cryst. A 70, C279 (2014) 
22. C. Jelsch, S. Soudani, C. Ben Nasr, IUCr J. 2, 327 (2015)

23. C. Jelsch, C. Ejsmont, L. Huder, IUCrJ 1, 119 (2014)

24. M. A. Spackman, D. Jayatilaka, CrystEngComm 11, 19 (2009)

25. M. Belhouchet, M. Bahri, J. M. Savariault, T. Mhiri, Spectrochim. Acta A 61, 387 (2005)

26. N. L. Calve, F. Romain, M. H. Limage, A. Novak, J. Mol. Struct. 200, 131 (1989)

27. S. Shanmuga Sundara Raj, H. K. Fun, P. S. Zhao, F. F. Jian, L. D. Lu, X. J. Yang, X. Wan, Acta Crystallogr. C 56, 742 (2000)

28. K. Kamel, A. Rayes, C. Ben Nasr, M. Rzaigui, F. Lefebvre, Mat. Res. Bull. 38, 741 (2003)

29. A. Oueslati, A. Rayes, C. Ben Nasr, F. Lefebvre. Mat. Res. Bull. 40, 1680 (2005)

30. A. Oueslati, C. Ben Nasr, A. Durif, F. Lefebvre. Mat. Res. Bull.40, 970 (2005) 


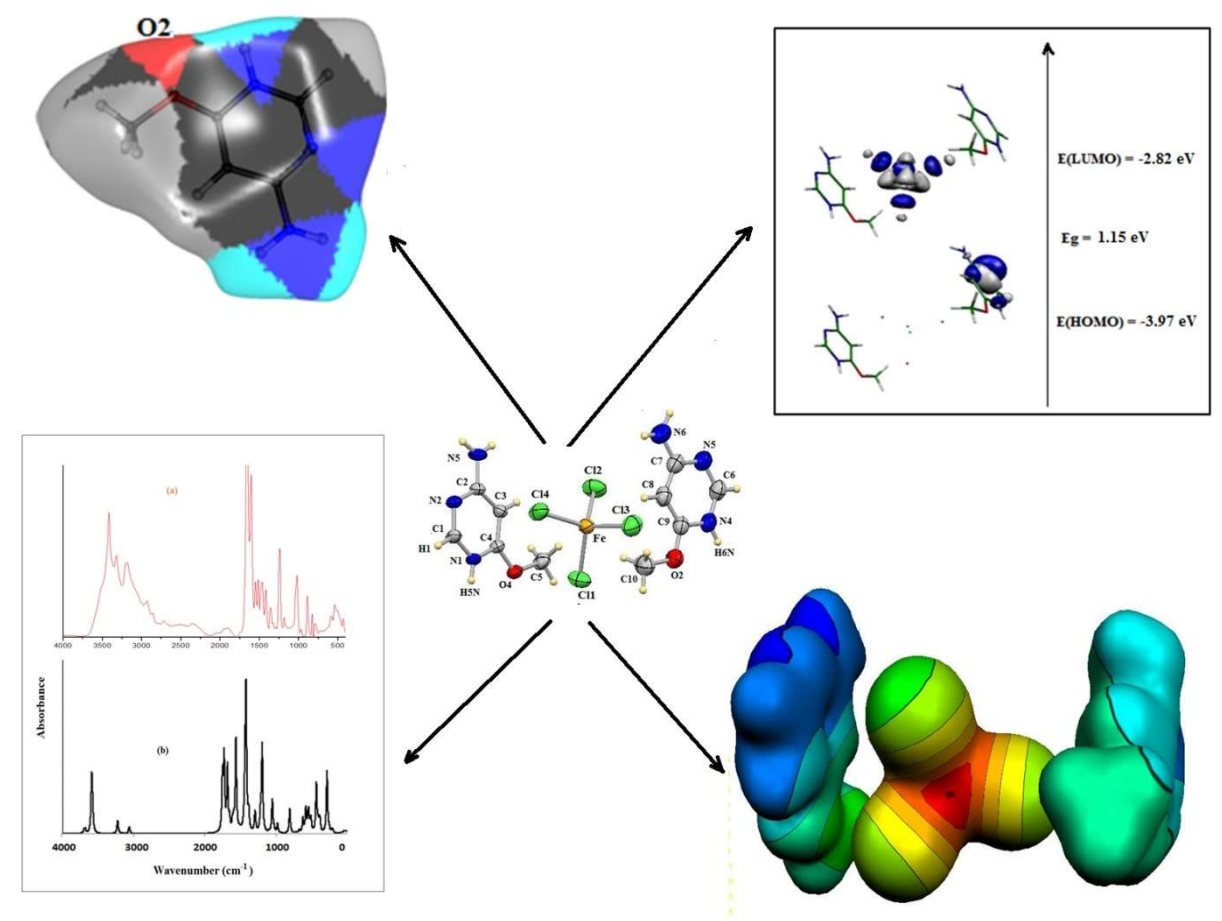

\section{Graphical abstract}

\section{SUPPLEMENT : CIF FILE}

data_shelx

_audit_creation_method 'SHELXL-2014/7'

_shelx_SHELXL_version_number ' '2014/7'

_chemical_name_systematic ? 


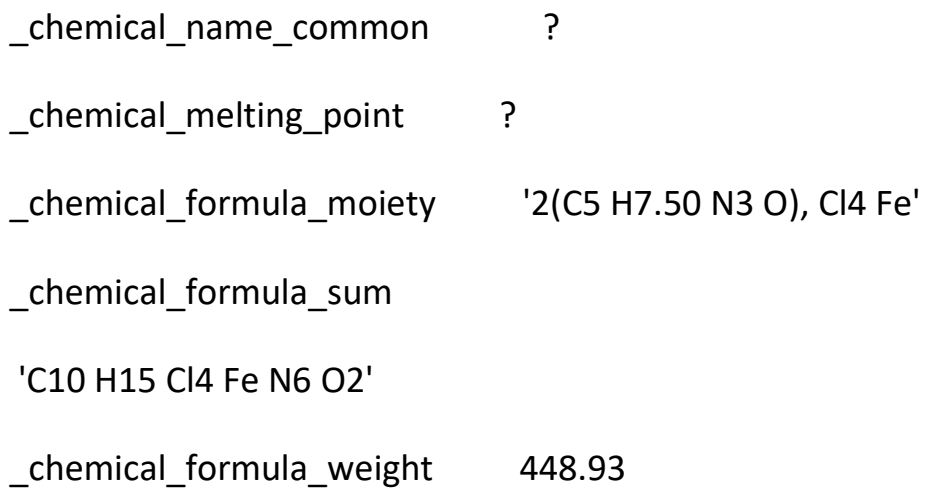




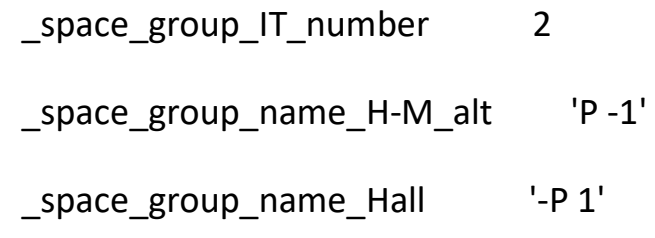

The symmetry employed for this shelxI refinement is uniquely defined by the following loop, which should always be used as a source of symmetry information in preference to the above space-group names. They are only intended as comments. ;

loop_ _space_group_symop_operation_xyz

'x, $y, z^{\prime}$

'-x, $-\mathrm{y},-\mathrm{z}^{\prime}$

_cell_length_a

$6.6406(2)$

_cell_length_b

$7.4042(3)$

_cell_length_c

$19.6212(7)$

_cell_angle_alpha

$88.350(3)$

_cell_angle_beta

$87.005(3)$

_cell_angle_gamma

$77.210(2)$

_cell_volume

$939.37(6)$

_cell_formula_units_Z 2

_cell_measurement_temperature 295

_cell_measurement_reflns_used 12546 


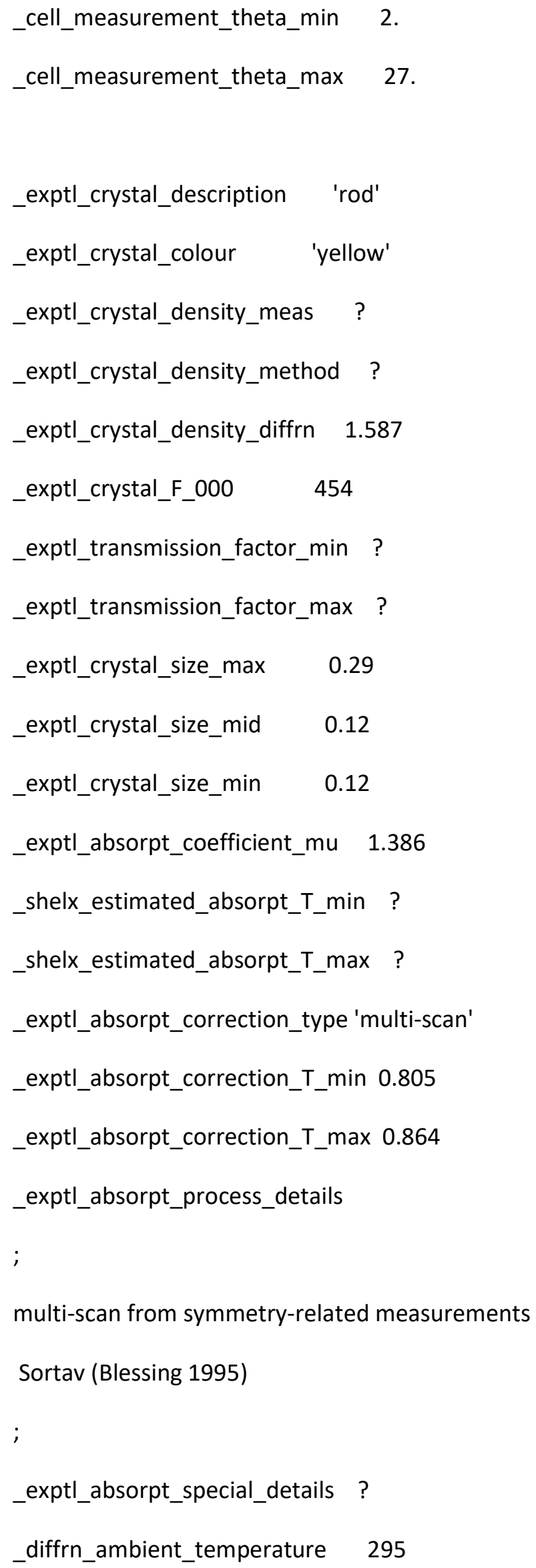




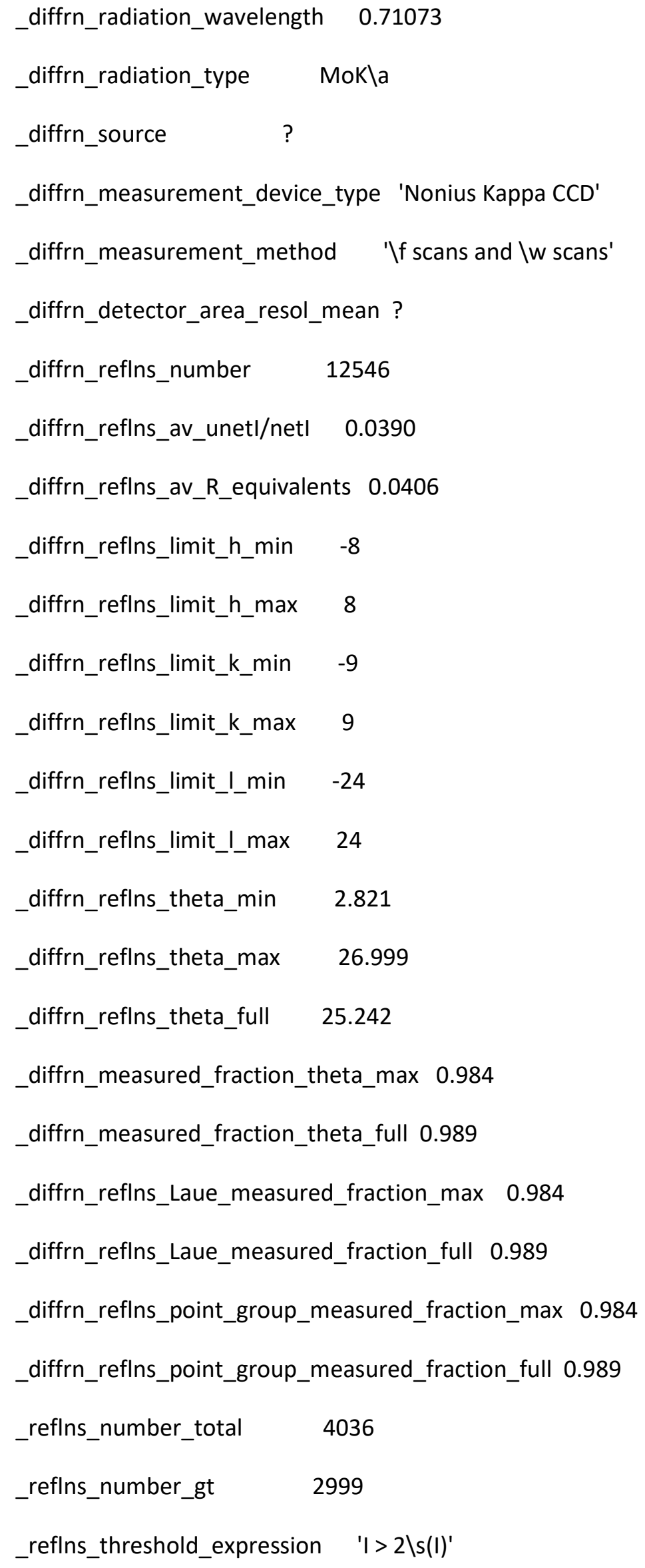


_reflns_Friedel_coverage $\quad 0.000$

_reflns_Friedel_fraction_max .

_reflns_Friedel_fraction_full .

_reflns_special_details

;

Reflections were merged by SHELXL according to the crystal class for the calculation of statistics and refinement.

_reflns_Friedel_fraction is defined as the number of unique Friedel pairs measured divided by the number that would be possible theoretically, ignoring centric projections and systematic absences.

_computing_data_collection 'Kappa CCD server software (Nonius, 1997)'

_computing_cell_refinement 'DENZO-SMN (Otwinowski \& Minor, 1997)'

_computing_data_reduction 'DENZO-SMN (Otwinowski \& Minor, 1997)'

_computing_structure_solution 'SIR97 (Altomare et al.,1999)'

_computing_structure_refinement 'SHELXL-2014/7 (Sheldrick, 2014)'

_computing_molecular_graphics 'ORTEPIII (Burnett \& Johnson, 1996)'

_computing_publication_material

;

SHELXL-2014/7 (Sheldrick, 2014; WINGX (Farrugia, 1999)

;

_refine_special_details ?

_refine_Is_structure_factor_coef Fsqd 
_refine_ls_matrix_type full

_refine_ls_weighting_scheme_calc

_refine_Is_weighting_details

$' w=1 /\left[\backslash s^{\wedge} 2^{\wedge}\left(F o^{\wedge} 2^{\wedge}\right)+(0.0460 P)^{\wedge} 2^{\wedge}+0.3788 P\right]$ where $P=\left(F o^{\wedge} 2^{\wedge}+2 F c^{\wedge} 2^{\wedge}\right) / 3^{\prime}$

_atom_sites_solution_primary ?

_atom_sites_solution_secondary ?

_atom_sites_solution_hydrogens mixed

_refine_Is_hydrogen_treatment mixed

_refine_Is_extinction_method none

_refine_Is_extinction_coef .

_refine_Is_number_reflns 4036

_refine_Is_number_parameters 232

_refine_Is_number_restraints 4

_refine_Is_R_factor_all 0.0594

_refine_Is_R_factor_gt 0.0394

_refine_Is_wR_factor_ref 0.1059

_refine_Is_wR_factor_gt 0.0958

_refine_Is_goodness_of_fit_ref 1.037

_refine_Is_restrained_S_all 1.037

_refine_Is_shift/su_max 0.002

_refine_Is_shift/su_mean $\quad 0.000$

loop_

_atom_site_label

_atom_site_type_symbol

_atom_site_fract_x

_atom_site_fract_y 
_atom_site_fract_z

_atom_site_U_iso_or_equiv

_atom_site_adp_type

_atom_site_occupancy

_atom_site_site_symmetry_order

_atom_site_calc_flag

_atom_site_refinement_flags_posn

_atom_site_refinement_flags_adp

_atom_site_refinement_flags_occupancy

_atom_site_disorder_assembly

_atom_site_disorder_group

Fe1 Fe $-0.01777(6) 0.17835(5)$ 0.74923(2) 0.04930(13) Uani $11 \mathrm{~d} \ldots \ldots$

Cl1 Cl 0.08919(13) 0.42712(11) 0.71530(5) 0.0755(2) Uani $11 \mathrm{~d} \ldots \ldots$

$\mathrm{Cl} 2 \mathrm{Cl}-0.34561(13) 0.24820(14) 0.78027(5) 0.0876(3)$ Uani $11 \mathrm{~d} \ldots \ldots$

$\mathrm{Cl} 4 \mathrm{Cl}$ 0.02574(15) $-0.01174(15) 0.66428(5)$ 0.0897(3) Uani $11 \mathrm{~d} \ldots \ldots$

Cl5 Cl 0.15814(17) 0.05199(15) 0.83599(5) 0.0934(3) Uani $11 \mathrm{~d} . \ldots$.

$010-0.2548(3) 0.6439(2) 0.59584(9)$ 0.0515(4) Uani $11 \mathrm{~d} \ldots \ldots$

$\mathrm{O} 200.6769(4)-0.1833(3) 0.90255(12) 0.0757(6)$ Uani $11 \mathrm{~d} \ldots \ldots$

N1 N -0.1522(3) 0.4152(3) 0.52166(11) 0.0444(5) Uani $11 \mathrm{~d} \ldots \ldots$

$\mathrm{N} 2 \mathrm{~N}-0.3251(3) 0.1737(3) 0.50713(11) 0.0477(5)$ Uani $11 \mathrm{~d} \ldots \ldots$

N3 N -0.6201(4) 0.1635(4) 0.57128(14) 0.0609(6) Uani $11 \mathrm{~d} \mathrm{D} \mathrm{.} \mathrm{.} \mathrm{.}$

N4 N 0.4199(5) $-0.1437(4) 0.98201(13) 0.0664(7)$ Uani $11 \mathrm{~d} \ldots .$.

N5 N 0.1744(5) -0.3301(4) 0.99590(14) 0.0750(7) Uani $11 \mathrm{~d} \ldots \ldots$

N6 N 0.1944(6) -0.5771(5) 0.9261(2) 0.0892(9) Uani $11 \mathrm{~d}$ D . . . .

C1 C -0.1762(4) 0.2620(4) 0.49284(13) 0.0481(6) Uani $11 \mathrm{~d} \ldots .$.

H1 H -0.0778 0.2119 0.4591 0.058 Uiso 11 calc R U . . .

C2 C $-0.4663(4) 0.2479(3)$ 0.55745(12) 0.0432(5) Uani $11 \mathrm{~d} \ldots \ldots$ 
C3 C -0.4503(4) 0.4065(3) 0.59177(12) 0.0433(5) Uani $11 \mathrm{~d} \ldots .$. H4 H -0.5445 0.45440 .62700 .052 Uiso 11 calc R U . . C4 C -0.2918(4) 0.4884(3) 0.57175(12) 0.0408(5) Uani $11 \mathrm{~d} \ldots .$. C5 C -0.3884(5) 0.7292(4) 0.65168(16) 0.0616(7) Uani $11 \mathrm{~d} \ldots .$. H6A H -0.5276 0.7662 0.63710.092 Uiso 11 calc R U . . . H6B H -0.3431 0.83600 .66600 .092 Uiso 11 calc R U . . . H6C H - 0.38360 .64220 .68910 .092 Uiso 11 calc $R$ U . . . C6 C $0.2561(6)-0.1926(5)$ 1.01236(17) 0.0731(9) Uani $11 \mathrm{~d} . . .$. H7 H $0.1928-0.12181 .04910 .088$ Uiso 11 calc R U . . . C7 C 0.2713(5) -0.4327(5) 0.94251(17) 0.0692(8) Uani $11 \mathrm{~d} \ldots .$. C8 C 0.4416(5) -0.3901(4) 0.90652(16) 0.0677(8) Uani $11 \mathrm{~d} \ldots .$. H10 H $0.5032-0.45870 .86900 .081$ Uiso 11 calc R U . . . C9 C 0.5151(5) -0.2442(4) 0.92817(15) 0.0634(8) Uani $11 \mathrm{~d}$. . . . . C10 C $0.7828(7)-0.2727(6) 0.8425(2)$ 0.0980(13) Uani $11 \mathrm{~d} \ldots .$. H12A H $0.8303-0.40270 .85190 .147$ Uiso 11 calc R U . . H12B H $0.8989-0.21940 .82960 .147$ Uiso 11 calc R U . . . H12C H $0.6898-0.25550 .80580 .147$ Uiso 11 calc R U . . H1N H -0.714(4) 0.208(4) 0.6017(13) 0.062(9) Uiso $11 d$ D . . . H2N H -0.630(5) 0.069(3) 0.5477(15) 0.066(9) Uiso $11 \mathrm{~d}$ D . . . H3N H 0.263(6) -0.647(5) 0.8940(16) 0.088(13) Uiso $11 \mathrm{~d} \mathrm{D} \mathrm{...}$ H4N H 0.093(5) -0.609(6) 0.951(2) 0.106(15) Uiso $11 \mathrm{~d} D \ldots$ H5N H -0.065(6) 0.471(6) 0.509(2) 0.024(11) Uiso $0.51 \mathrm{~d} \ldots . \mathrm{P} .$. H6N H 0.468(11) -0.050(10) 0.992(4) 0.07(2) Uiso 0.51 d . . . . .

loop_ _atom_site_aniso_label _atom_site_aniso_U_11 
_atom_site_aniso_U_22

_atom_site_aniso_U_33

_atom_site_aniso_U_23

_atom_site_aniso_U_13

_atom_site_aniso_U_12

Fe1 $0.0470(2) 0.0520(2) 0.0498(2)-0.00817(16) 0.00521(15)-0.01378(16)$

Cl1 0.0717(5) 0.0569(4) 0.0978(6) 0.0012(4) 0.0189(4) -0.0196(4)

Cl2 0.0563(5) 0.0951(7) 0.1091(7) -0.0191(5) 0.0291(4) -0.0171(4)

Cl4 0.0902(6) 0.1075(7) 0.0857(6) -0.0528(5) 0.0358(5) -0.0549(5)

Cl5 0.1053(7) 0.0912(7) 0.0909(6) 0.0202(5) -0.0373(6) -0.0326(6)

$010.0557(11) 0.0500(10) 0.0556(10)-0.0149(8) 0.0049(8)-0.0261(8)$

$020.0928(17) 0.0729(15) 0.0659(13)-0.0164(11) 0.0051(12)-0.0277(12)$

N1 $0.0407(11) 0.0499(12) 0.0486(11)-0.0092(9) 0.0073(9)-0.0241(9)$

N2 $0.0503(12) 0.0456(12) 0.0536(12)-0.0096(9) 0.0065(9)-0.0249(9)$

N3 $0.0621(15) 0.0584(15) 0.0718(16)-0.0121(13) 0.0196(12)-0.0377(12)$

N4 $0.0798(19) 0.0633(17) 0.0578(15)-0.0131(13)-0.0071(13)-0.0171(14)$

N5 0.0795(19) 0.0772(19) 0.0703(17) -0.0131(14) -0.0049(14) -0.0199(15)

N6 0.100(3) $0.083(2) 0.092(2)-0.0207(19) 0.000(2)-0.036(2)$

C1 $0.0435(13) 0.0518(15) 0.0532(14)-0.0145(11) 0.0097(11)-0.0209(11)$

C2 $0.0447(13) 0.0437(13) 0.0457(13) 0.0014(10) 0.0019(10)-0.0203(10)$

C3 $0.0443(13) 0.0464(13) 0.0422(12)-0.0050(10) 0.0076(10)-0.0177(10)$

C4 0.0426(13) $0.0406(13) 0.0431(12)-0.0025(10)-0.0031(10)-0.0169(10)$

C5 $0.0675(18) 0.0570(17) 0.0633(17)-0.0231(14) 0.0032(14)-0.0187(14)$

C6 $0.080(2) 0.077(2) 0.0609(18)-0.0169(16)-0.0038(16)-0.0139(18)$

C7 $0.077(2) 0.0636(19) 0.0685(19)-0.0037(15)-0.0180(16)-0.0144(16)$

C8 $0.085(2) 0.0620(18) 0.0559(17)-0.0111(14)-0.0060(15)-0.0129(16)$

C9 $0.078(2) 0.0594(18) 0.0530(16)-0.0043(13)-0.0095(14)-0.0131(15)$ 
C10 0.123(4) $0.096(3) 0.082(2)-0.026(2) 0.028(2)-0.044(3)$

_geom_special_details

;

All esds (except the esd in the dihedral angle between two I.s. planes)

are estimated using the full covariance matrix. The cell esds are taken

into account individually in the estimation of esds in distances, angles

and torsion angles; correlations between esds in cell parameters are only

used when they are defined by crystal symmetry. An approximate (isotropic)

treatment of cell esds is used for estimating esds involving I.s. planes.

;

loop_

_geom_bond_atom_site_label_1

_geom_bond_atom_site_label_2

_geom_bond_distance

_geom_bond_site_symmetry_2

_geom_bond_publ_flag

$\mathrm{Fe} 1 \mathrm{Cl} 4$ 2.1789(8) . ?

$\mathrm{Fe} 1 \mathrm{Cl} 2$ 2.1815(9) . ?

$\mathrm{Fe} 1 \mathrm{Cl} 5$ 2.1840(10) . ?

Fe1 Cl1 2.1908(9) . ?

O1 C4 1.333(3) . ?

O1 C5 1.441(3) . ?

02 C9 1.325(4) . ?

O2 C10 1.440(4) . ?

N1 C1 1.326(3) . ? 
N1 C4 1.354(3) . ?

N1 H5N 0.81(4) . ?

N2 C1 1.315(3) . ?

N2 C2 1.365(3) . ?

N3 C2 1.323(3) . ?

N3 H1N 0.857(17) . ?

N3 H2N 0.868(18) . ?

N4 C6 1.328(5) . ?

N4 C9 1.355(4) . ?

N4 H6N 0.85(6) . ?

N5 C6 1.311(4) . ?

N5 C7 1.359(4) . ?

N6 C7 1.336(5) . ?

N6 H3N 0.872(18) . ?

N6 H4N 0.881(19) . ?

C1 H1 0.9300 . ?

C2 C3 1.397(3) . ?

C3 C4 1.362(3) . ?

C3 H4 0.9300 .?

C5 H6A 0.9600 . ?

C5 H6B 0.9600 . ?

C5 H6C 0.9600 . ?

C6 H7 0.9300 .?

C7 C8 1.392(5) . ?

C8 C9 1.367(4) . ?

C8 H10 0.9300.?

$\mathrm{C} 10 \mathrm{H} 12 \mathrm{~A} 0.9600$.? 
C10 H12B 0.9600 . ?

$\mathrm{C} 10 \mathrm{H} 12 \mathrm{C} 0.9600$. ?

loop_

_geom_angle_atom_site_label_1

_geom_angle_atom_site_label_2

_geom_angle_atom_site_label_3

_geom_angle

_geom_angle_site_symmetry_1

_geom_angle_site_symmetry_3

_geom_angle_publ_flag

$\mathrm{Cl} 4 \mathrm{Fe} 1 \mathrm{Cl} 2$ 108.54(4) . . ?

$\mathrm{Cl} 4 \mathrm{Fe} 1 \mathrm{Cl} 5$ 111.02(5) . . ?

Cl2 Fe1 Cl5 109.03(5) . . ?

Cl4 Fe1 Cl1 108.50(4) . . ?

Cl2 Fe1 Cl1 110.64(4) . . ?

Cl5 Fe1 Cl1 109.12(4) . . ?

C4 01 C5 117.0(2) . . ?

C9 02 C10 117.2(3) . . ?

C1 N1 C4 117.6(2) . . ?

C1 N1 H5N 123(3) . . ?

C4 N1 H5N 119(3) . . ?

C1 N2 C2 115.8(2) . . ?

C2 N3 H1N 119(2) . . ?

C2 N3 H2N 120(2) . . ?

H1N N3 H2N 121(3) . . ?

C6 N4 C9 117.9(3) . . ? 
C6 N4 H6N 126(5) .. ?

C9 N4 H6N 116(5) .. ?

C6 N5 C7 115.5(3) . . ?

C7 N6 H3N 116(3) . . ?

C7 N6 H4N 121(3) . . ?

H3N N6 H4N 122(4) . . ?

N2 C1 N1 126.6(2) . . ?

N2 C1 H1 116.7 . . ?

N1 C1 H1 116.7 . . ?

N3 C2 N2 116.6(2) . . ?

N3 C2 C3 121.9(2) . . ?

N2 C2 C3 121.5(2) . . ?

C4 C3 C2 117.6(2) . . ?

C4 C3 H4 121.2 . . ?

C2 C3 H4 121.2 .. ?

O1 C4 N1 112.23(19) . . ?

O1 C4 C3 126.8(2) . . ?

N1 C4 C3 120.9(2). . ?

O1 C5 H6A 109.5 . . ?

O1 C5 H6B 109.5 .. ?

H6A C5 H6B 109.5 . . ?

O1 C5 H6C 109.5 . . ?

H6A C5 H6C 109.5 . . ?

H6B C5 H6C 109.5 .. ?

N5 C6 N4 126.8(3) . . ?

N5 C6 H7 116.6 . .?

N4 C6 H7 116.6 . . ? 
N6 C7 N5 116.5(4) .. ?

N6 C7 C8 121.5(3) . . ?

N5 C7 C8 122.0(3) . . ?

C9 C8 C7 117.8(3) . . ?

C9 C8 H10 121.1 . . ?

C7 C8 H10 121.1 . . ?

O2 C9 N4 112.4(3) . . ?

O2 C9 C8 127.6(3) . . ?

N4 C9 C8 120.1(3) . . ?

O2 C10 H12A 109.5 . . ?

O2 C10 H12B 109.5 . . ?

H12A C10 H12B 109.5 . . ?

$\mathrm{O} 2 \mathrm{C} 10 \mathrm{H} 12 \mathrm{C} 109.5$. . ?

H12A C10 H12C 109.5 . . ?

H12B C10 H12C 109.5 . .?

loop_

_geom_hbond_atom_site_label_D

_geom_hbond_atom_site_label_H

_geom_hbond_atom_site_label_A

_geom_hbond_distance_DH

_geom_hbond_distance_HA

_geom_hbond_distance_DA

_geom_hbond_angle_DHA

_geom_hbond_site_symmetry_A

C1 H1 Cl4 0.932 .84 3.623(3) 142.5 2_556

C3 H4 Cl1 $0.932 .953 .780(2) 148.9$ 1_455 
C5 H6B Cl4 $0.962 .913 .707(3) 140.81$ 1_565

C8 H10 Cl2 $0.932 .803 .694(3) 162.5$ 1_645

C10 H12B Cl5 0.962 .93 3.822(4) 155.11_655

N3 H1N Cl1 $0.857(17) 2.88(2) 3.688(3)$ 159(3) 1_455

N3 H1N Cl4 $0.857(17) 2.84(3)$ 3.363(2) 121(2) 1_455

N3 H2N N2 $0.868(18)$ 2.203(19) 3.069(3) 175(3) 2_456

N6 H3N Cl5 0.872(18) 2.77(3) 3.368(4) 127(3) 1_545

N6 H4N N5 0.881(19) 2.14(2) 3.018(5) 174(4) 2_547

N1 H5N N1 0.81(4) 1.89(4) 2.695(4) 176(5) 2_566

_refine_diff_density_max 0.634

_refine_diff_density_min -0.467

_refine_diff_density_rms 0.052

_shelx_res_file

;

shelx.res created by SHELXL-2014/7

TITL kk

CELL $0.71073 \quad 6.6406 \quad 7.4042 \quad 19.621288 .350087 .005077 .2100$

$\begin{array}{lllllllll}\text { ZERR } & 2 & 0.0002 & 0.0003 & 0.0007 & 0.0025 & 0.0026 & 0.0024\end{array}$

LATT 1

SFAC Fe ClC H N O

DISP Fe $0.34630 \quad 0.84440$

DISP Cl $0.14840 \quad 0.15850$ 
DISP C $\quad 0.00330 \quad 0.00160$

DISP H $\quad 0.00000 \quad 0.00000$

DISP N $0.00610 \quad 0.00330$

DISP O $0.01060 \quad 0.00600$

$\begin{array}{lllllll}\text { UNIT } & 2 & 8 & 20 & 30 & 12 & 4\end{array}$

LIST 4

ACTA

BOND \$H

FMAP 2

PLAN - 20 .5 .5

omit -3 54 .

htab

L.S. 12

EQIV \$1 - $x,-y,-z+1$

HTAB C1 Cl4_\$1

EQIV $\$ 2 x-1, y, z$

HTAB C3 Cl1_\$2

EQIV $\$ 3 x, y+1, z$

HTAB C5 Cl4_\$3

EQIV $\$ 4 x+1, y-1, z$

HTAB C8 Cl2_\$4

EQIV $\$ 5 x+1, y, z$

HTAB C10 Cl5_\$5

HTAB N3 Cl1_\$2

HTAB N3 Cl4_\$2

EQIV \$6 -x-1, -y, -z+1

HTAB N3 N2_\$6 
EQIV $\$ 7 x, y-1, z$

HTAB N6 Cl5_\$7

EQIV \$8 -x, -y-1, -z+2

HTAB N6 N5_\$8

EQIV \$9 -x, - y+1, -z+1

HTAB N1 N1_\$9

dfix 0.880 .02 n3 H1n

dfix 0.880 .02 n3 H2n

dfix 0.880 .02 n6 H3n

dfix 0.880 .02 n6 H4n

WGHT $\quad 0.046000 \quad 0.378800$

FVAR $\quad 0.75481$

$\begin{array}{llllllll}\text { FE1 } & 1 & -0.017770 & 0.178351 & 0.749233 & 11.00000 & 0.04701 & 0.05203=\end{array}$ $0.04983-0.00817 \quad 0.00521-0.01378$

$\begin{array}{llllllll}\text { CL1 } & 2 & 0.089186 & 0.427123 & 0.715303 & 11.00000 & 0.07168 & 0.05694=\end{array}$ $\begin{array}{llll}0.09778 & 0.00119 & 0.01889 & -0.01958\end{array}$

$\begin{array}{llllllll}\text { CL2 } & 2 & -0.345607 & 0.248198 & 0.780266 & 11.00000 & 0.05629 & 0.09514=\end{array}$ $\begin{array}{llll}0.10914 & -0.01907 & 0.02908 & -0.01707\end{array}$

$\begin{array}{llllllll}\text { CL4 } & 2 & 0.025741 & -0.011737 & 0.664278 & 11.00000 & 0.09023 & 0.10745=\end{array}$ $0.08567 \quad-0.05279 \quad 0.03578-0.05491$

$\begin{array}{llllllll}\text { CL5 } & 2 & 0.158138 & 0.051987 & 0.835989 & 11.00000 & 0.10535 & 0.09123=\end{array}$ $0.09091 \quad 0.02019-0.03732-0.03261$

$\begin{array}{llllllll}01 & 6 & -0.254776 & 0.643881 & 0.595843 & 11.00000 & 0.05574 & 0.04997=\end{array}$ $0.05559-0.01487 \quad 0.00490-0.02611$

$\begin{array}{llllllll}02 & 6 & 0.676872 & -0.183337 & 0.902552 & 11.00000 & 0.09281 & 0.07290=\end{array}$ $0.06585-0.01638 \quad 0.00510-0.02771$

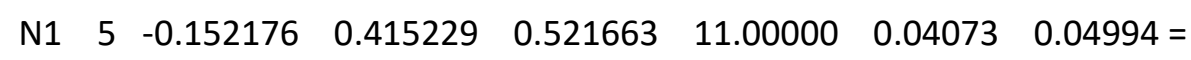




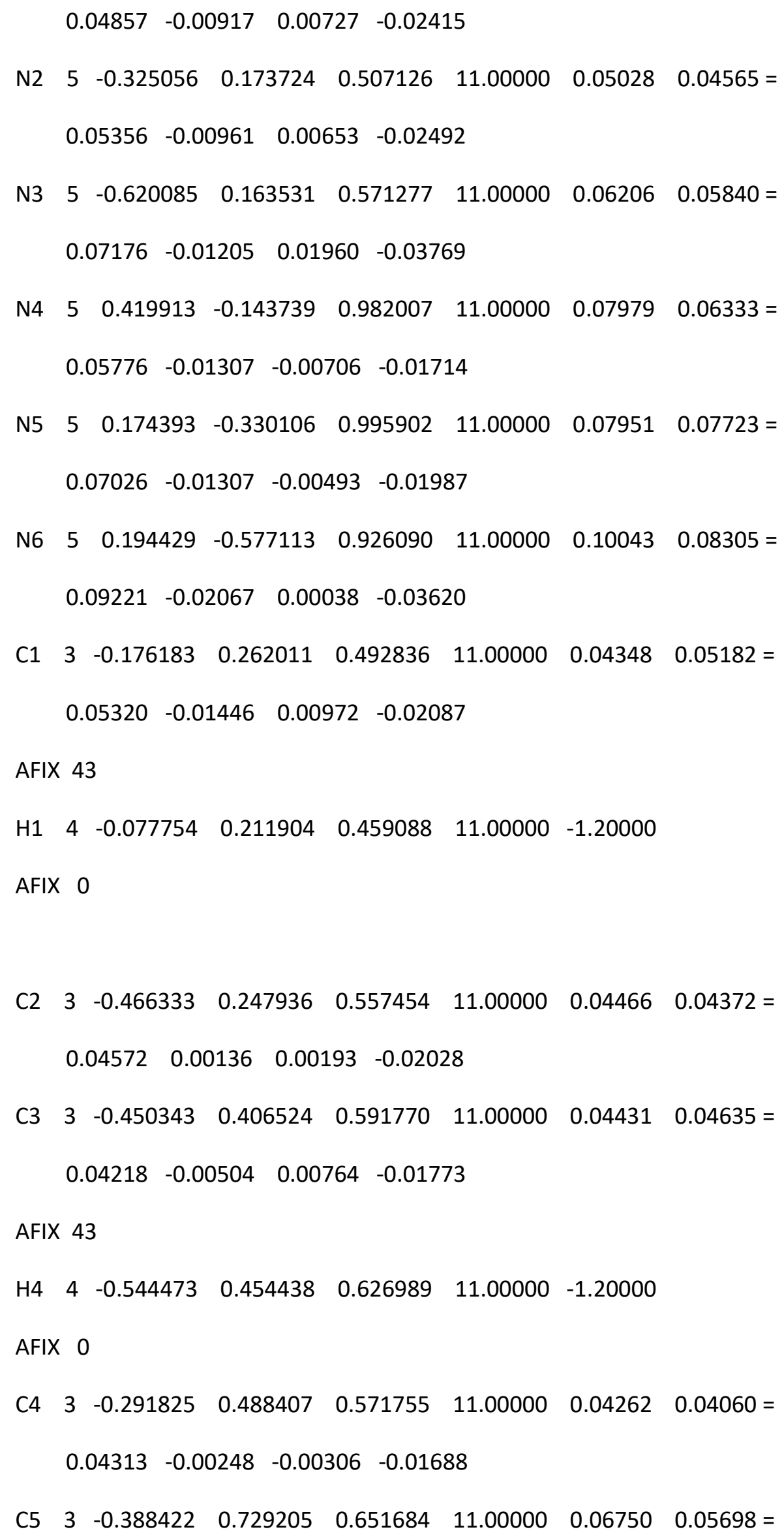




$$
0.06332-0.02310 \quad 0.00324-0.01871
$$

\section{AFIX 133}

$\begin{array}{lllllll}\text { H6A } & 4 & -0.527583 & 0.766250 & 0.637131 & 11.00000 & -1.50000\end{array}$

$\begin{array}{lllllll}\text { H6B } & 4 & -0.343111 & 0.835998 & 0.665998 & 11.00000 & -1.50000\end{array}$

$\begin{array}{lllllll}\text { H6C } & 4 & -0.383591 & 0.642200 & 0.689119 & 11.00000 & -1.50000\end{array}$

AFIX 0

$\begin{array}{lllllll}\text { C6 } 3 & 0.256135 & -0.192596 & 1.012358 & 11.00000 & 0.08018 & 0.07746=\end{array}$ $0.06091-0.01687-0.00382-0.01394$

AFIX 43

H7 $4 \begin{array}{llllll}0.192786 & -0.121839 & 1.049145 & 11.00000 & -1.20000\end{array}$ AFIX 0

$\begin{array}{llllllll}\text { C7 } & 3 & 0.271256 & -0.432695 & 0.942515 & 11.00000 & 0.07656 & 0.06361=\end{array}$ $0.06853-0.00371-0.01795-0.01443$

$\begin{array}{llllllll}\text { C8 } & 3 & 0.441553 & -0.390117 & 0.906523 & 11.00000 & 0.08463 & 0.06205=\end{array}$ $0.05590-0.01114-0.00601-0.01293$

AFIX 43

$\begin{array}{lllllll}H 10 & 4 & 0.503212 & -0.458680 & 0.869018 & 11.00000 & -1.20000\end{array}$

AFIX 0

$\begin{array}{llllllll}\text { C9 } & 3 & 0.515065 & -0.244151 & 0.928169 & 11.00000 & 0.07769 & 0.05939=\end{array}$ $0.05301-0.00429-0.00950-0.01309$

$\begin{array}{llllllll}\mathrm{C} 10 & 3 & 0.782793 & -0.272699 & 0.842461 & 11.00000 & 0.12304 & 0.09567=\end{array}$ $0.08239 \quad-0.02558 \quad 0.02843 \quad-0.04382$

AFIX 133

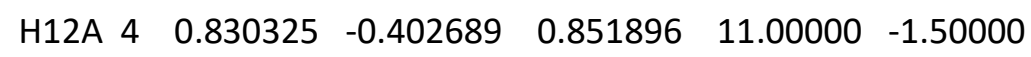

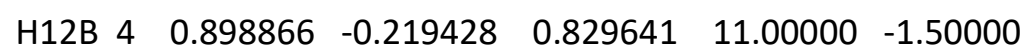

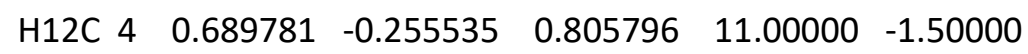


AFIX 0

$\begin{array}{lllllll}\text { H1N } & 4 & -0.713825 & 0.208341 & 0.601689 & 11.00000 & 0.06178\end{array}$

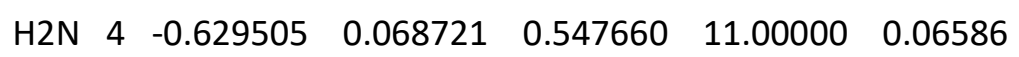

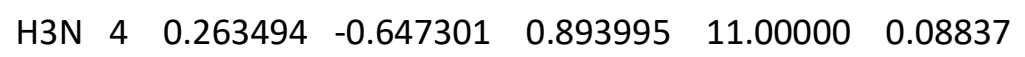

$\begin{array}{lllllll}\text { H4N } & 4 & 0.093157 & -0.609180 & 0.950891 & 11.00000 & 0.10648\end{array}$

$\begin{array}{lllllll}H 5 N & 4 & -0.064962 & 0.470529 & 0.508626 & 10.50000 & 0.02427\end{array}$

$\begin{array}{lllllll}\text { H6N } & 4 & 0.467751 & -0.050434 & 0.991662 & 10.50000 & 0.07042\end{array}$

HKLF 4

REM kk

REM R1 $=0.0394$ for $2999 \mathrm{Fo}>4 \operatorname{sig}(\mathrm{Fo})$ and 0.0594 for all 4036 data

REM 232 parameters refined using 4 restraints

END

WGHT $\quad 0.0443 \quad 0.3969$

REM Instructions for potential hydrogen bonds

HTAB C1 Cl4_\$1

HTAB C3 Cl1_\$2

HTAB C5 Cl4_\$3

HTAB C8 Cl2_\$4

HTAB C10 Cl5_\$5

HTAB N3 Cl1_\$2

HTAB N3 Cl4_\$2

HTAB N3 N2_\$6 
HTAB N6 Cl5_\$7

HTAB N6 N5_\$8

HTAB N1 N1_\$9

EQIV $\$ 10-x+1,-y,-z+2$

HTAB N4 N4_\$10 